\title{
Tomographic retrieval of water vapour and temperature around polar mesospheric clouds using Odin-SMR
}

\author{
O. M. Christensen ${ }^{1}$, P. Eriksson ${ }^{1}$, J. Urban ${ }^{1, \dagger}$, D. Murtagh ${ }^{1}$, K. Hultgren ${ }^{2}$, and J. Gumbel ${ }^{2}$ \\ ${ }^{1}$ Department of Earth and Space Sciences, Chalmers University of Technology, Gothenburg, Sweden \\ ${ }^{2}$ Department of Meteorology, Stockholm University, Stockholm, Sweden \\ $\dagger$ deceased, 14 August 2014
}

Correspondence to: O. M. Christensen (ole.m.christensen@chalmers.se)

Received: 8 October 2014 - Published in Atmos. Meas. Tech. Discuss.: 28 November 2014

Revised: 8 April 2015 - Accepted: 10 April 2015 - Published: 6 May 2015

\begin{abstract}
A special observation mode of the Odin satellite provides the first simultaneous measurements of water vapour, temperature and polar mesospheric cloud (PMC) brightness over a large geographical area while still resolving both horizontal and vertical structures in the clouds and background atmosphere. The observation mode was activated during June, July and August of 2010 and 2011, and for latitudes between 50 and $82^{\circ} \mathrm{N}$.

This paper focuses on the water vapour and temperature measurements carried out with Odin's sub-millimetre radiometer (SMR). The tomographic retrieval approach used provides water vapour and temperature between 75 and $90 \mathrm{~km}$ with a vertical resolution of about $2.5 \mathrm{~km}$ and a horizontal resolution of about $200 \mathrm{~km}$. The precision of the measurements is estimated to $0.2 \mathrm{ppmv}$ for water vapour and $2 \mathrm{~K}$ for temperature. Due to limited information about the pressure at the measured altitudes, the results have large uncertainties $(>3 \mathrm{ppmv})$ in the retrieved water vapour. These errors, however, influence mainly the mean atmosphere retrieved for each orbit, and variations around this mean are still reliably captured by the measurements.

SMR measurements are performed using two different mixer chains, denoted as frequency mode 19 and 13. Systematic differences between the two frontends have been noted. A first comparison with the Solar Occultation For Ice Experiment instrument (SOFIE) on-board the Aeronomy of Ice in the Mesosphere (AIM) satellite and the Fourier Transform Spectrometer of the Atmospheric Chemistry Experiment (ACE-FTS) on-board SCISAT indicates that the measurements using the frequency mode 19 have a significant low bias in both temperature $(>15 \mathrm{~K})$ and water
\end{abstract}

vapour ( $>0.5 \mathrm{ppmv})$, while the measurements using frequency mode 13 agree with the other instruments considering estimated errors.

PMC brightness data is provided by OSIRIS, Odin's other sensor. Combined SMR and OSIRIS data for some example orbits is considered. For these orbits, effects of PMCs on the water vapour distribution are clearly seen. Areas depleted of water vapour are found above layers with PMC, while regions of enhanced water vapour due to ice particle sedimentation are primarily placed between and under the clouds.

\section{Introduction}

Noctilucent, or Polar mesospheric clouds (PMCs) are iceclouds that form in the summer mesopause region at high latitudes. During the last 30 years there has been much research focused on understanding the formation and development of these clouds. In particular, the question has been raised as to how these clouds are responding to the anthropogenic release of greenhouse gases (Thomas et al., 1989), and whether or not these clouds could be used as an indicator of large-scale climate change affecting the mesopause region (von Zahn, 2003; Thomas et al., 2003).

To accurately understand possible changes and predict the future of PMCs, we need to understand the micro-physical properties of the clouds and the conditions under which they form (Rapp and Thomas, 2006; Lübken et al., 2007). The formation of PMCs is governed by the amount of supersaturation of the local atmosphere, thus good measurements of temperature and water vapour in the mesopause region are 
needed to accurately assess models and to identify the processes involved in the creation and sublimation of PMCs (Russell et al., 2009).

Water vapour and temperature in the vicinity of PMCs have been measured in several studies using ground-, satellite- as well as rocket-based instruments (e.g. Lübken et al., 1999; Seele and Hartogh, 1999; Sheese et al., 2011). However, for accurate comparisons to models, both water vapour and temperature should ideally be measured simultaneously. Such measurements are less common, and have to date mainly been provided by solar occulting instruments such as HALOE (McHugh et al., 2003), ACE-FTS (Zasetsky et al., 2009) and AIM-SOFIE (Hervig et al., 2009). These measurements have been used in several studies (e.g. Rong et al., 2012; Zasetsky et al., 2009) to investigate the relationship between the background atmosphere and PMCs.

Unfortunately, solar occulting instruments have a limitation when it comes to the horizontal sampling of the atmosphere. Since only one profile is generated in each hemisphere per orbit, latitudinal variations of the atmosphere can only be investigated on a seasonal basis using these instruments. Emission limb sounders can, unlike solar occulting instruments, provide global maps of water vapour and temperature across the entire PMC region within a day. And, unlike infrared emission sounders (López-Puertas et al., 2009; Feofilov et al., 2009), instruments operating in the microwave region do not have to account for non-LTE emissions. Accordingly, the microwave limb sounder (MLS) on board Aura has been used to study the latitudinal variations in cloud formation (Rong et al., 2014). However, due to the limited vertical resolution of MLS at the altitudes of concern, and the fact that a second satellite instrument (AIM-CIPS) had to be used for the PMC data, only horizontal variations could be studied.

For a complete picture of the relevant processes involved in the PMC formation, high resolution and good coverage in both the vertical and horizontal directions of the background atmosphere and the PMC distribution is required. In this paper we present a set of measurements by the sub-millimetre radiometer (SMR) on board the Odin satellite, which for the first time provides high-resolution water vapour and temperature measurements around PMCs with a large geographical coverage. Simultaneous measurements are performed of PMC brightness by the Optical Spectrograph and InfraRed Imager System (OSIRIS) on Odin, and as such the combined observations provide a unique data set useful for the study of PMC formation.

SMR measures a water vapour transition at $556.9 \mathrm{GHz}$. In the normal operational mode it scans the atmosphere between 10 and $110 \mathrm{~km}$, and retrieves both water vapour and temperature. These measurements have been used in earlier studies to investigate the water vapour distribution in the mesosphere and above (Lossow et al., 2009). However, since the instrument scans the entire middle atmosphere, the horizontal distance between measurements at the same tangent altitude can be over $1000 \mathrm{~km}$ (Lossow et al., 2007). The resulting horizontal sampling is thus of similar magnitude.

To increase the horizontal sampling rate, a set of measurements was made in a special "tomographic" mode during June, July and August 2010 and 2011. In this mode only altitudes between 75 and $90 \mathrm{~km}$ are scanned, which reduces the distance between scans to $200 \mathrm{~km}$, thus allowing for a much higher horizontal resolution. As an additional advantage, the increased density of measurements opens the possibility of tomographically retrieving the atmospheric fields using a 2D retrieval algorithm.

Tomographic retrieval from limb-sounding satellite instruments was first suggested by Carlotti (2001), which used a non-linear least squares retrieval to implement a "geo-fit" method that takes into account horizontal inhomogeneities along the line of sight. Since then, tomographic methods have been applied on several different limb sounding instruments (e.g. Degenstein et al., 2003; Steck et al., 2005; Carlotti, 2006; Puķite et al., 2008). Livesey et al. (2006) used a non-linear optimal estimation method to retrieve data from the Microwave Limb Sounder on board the Aura spacecraft. In this paper we apply a similar method to the tomographic Odin-SMR measurements. This allows a further improvement in resolution and information content of the tomographic mode retrievals compared to using the standard Odin-SMR 1-D processing.

The co-aligned measurements of PMC brightness performed by OSIRIS are described in Hultgren et al. (2013). A tomographic approach is used to retrieve both vertical and horizontal structures of the PMCs with a horizontal resolution down to $330 \mathrm{~km}$ and a vertical resolution of $1 \mathrm{~km}$. Combined, the two instruments on board Odin can thus provide measurements of water vapour, temperature and PMC brightness with a hitherto unprecedented spatial resolution and coverage. SMR also performed similar measurements of the Southern Hemisphere during 2011, but these lack colocated OSIRIS measurements, and have a slightly different measurement geometry, and as such will not be considered in this study.

The goal of this paper is to give a detailed description of the tomographic SMR retrievals, and assess their capabilities and limitations in the retrieval of the background atmosphere around PMCs. We will first describe the instrument and the measurement procedure (Sect. 2), before moving on to the retrieval methodology (Sect. 3). The first results from the measurements are shown in Sect. 4, and the accuracy and reliability of the measurements will be discussed in Sect. 5 . Finally, we compare the results to other satellite instruments and show some early results combining SMR and OSIRIS data before summarising our findings in Sect. 6 . 
Table 1. Overview of Odin orbits, dates and frequency modes (FM) where tomographic modes are performed.

\begin{tabular}{llllllll}
\hline Year & Dates & Orbit numbers & FM & Year & Dates & Orbit numbers & FM \\
\hline 2010 & 16-17 June & $50790-50804$ & 19 & 2011 & 15-16 June & $56233-56246$ & 19 \\
2010 & 14-15 July & $51209-51223$ & 19 & 2011 & 16-17 June & $56247-56261$ & 13 \\
2010 & 15-16 July & $51224-51238$ & 13 & 2011 & 17-18 July & $56711-56725$ & 19 \\
2010 & 12-13 August & $51642-51655$ & 13 & 2011 & 18-19 July & $56726-56740$ & 13 \\
2010 & 13-14 August & $51656-51671$ & 19 & 2011 & 18-19 August & $57190-57205$ & 19 \\
\hline
\end{tabular}

\section{Instrument}

\subsection{Odin tomographic mode}

The Odin satellite was launched in 2001 with a dual mission: at first the observation time was split between astronomy and aeronomy, but since 2007 has purely been dedicated to atmospheric measurements. It flies in a approximately $600 \mathrm{~km}$ sun-synchronous orbit with an inclination of $98^{\circ}$ and the ascending node at 18:00 LT. The satellite carries two instruments: the SMR and the OSIRIS. The instruments are coaligned and scan the atmosphere in a limb-scanning configuration, and during standard operation scan tangent altitudes between roughly 8 and $120 \mathrm{~km}$ (Murtagh et al., 2002).

The Odin satellite and its instruments have many different modes of operation. In this study we use measurements taken in a special "tomographic" mode. These measurements were performed during 3 consecutive days in each of June, July and August 2010 and 2011 (see Table 1). In this mode the two instruments only scan the atmosphere at altitudes between 75 and $90 \mathrm{~km}$ to specifically target the summer mesopause region. The tomographic mode is activated as the satellite crosses the equator, and measurements are made across the Northern Hemisphere. Figure 1 shows the coverage of the SMR tomographic mode during 1 day. As can be seen from the figure, large parts of the Northern Hemisphere are sampled by Odin over the course of a day.

Since the tangent altitudes of the tomographic mode are limited to $75-90 \mathrm{~km}$, the distance between each scan through the atmosphere is reduced from 1000 to $200 \mathrm{~km}$, compared to previous Odin measurements of water vapour in the mesopause (Lossow et al., 2007). The shorter distance between scans means that the line-of-sight through the atmosphere for each scan will overlap. Figure $1 \mathrm{~b}$ shows the lineof-sight from a set of SMR measurements as a function of altitude and angle along orbit, where $0^{\circ}$ is the ascending node and $180^{\circ}$ the descending node. The overlap between the scans can clearly be seen. The line-of-sight overlap means that in order to optimally retrieve information from these measurements, a tomographic retrieval approach should be used, hence the name "tomographic" mode. (a)
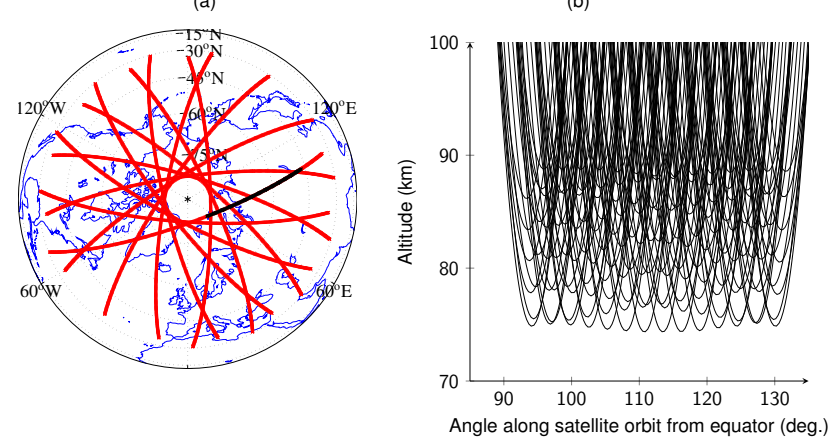

Figure 1. (a) Coverage of SMR tomographic measurements on 16 July 2010. The red points are the tangent positions for each spectrum. The spectra are processed in batches of 150 spectra, the tangent positions for the spectra in one such batch are shown by the black points. (b) The line-of-sight through the atmosphere for the measurements marked by the black points in (a).

\subsection{SMR}

This paper focuses on the tomographic mode measurements made by SMR. It measures radiation in five bands at around 118 and between $480-581 \mathrm{GHz}$, and can operate in several different frequency modes depending on the species of interest (Frisk et al., 2003). The tomographic mode uses either the $\mathrm{A} 1$ or $\mathrm{B} 2$ front-end, operating in the ranges 541-558 and $547-564 \mathrm{GHz}$, respectively, to measure the $\mathrm{H}_{2} \mathrm{O}$ spectral line at $556.9 \mathrm{GHz}$. This is achieved by setting the LO frequency to 553.05 and 553.302 for A1 and B2 frontends, respectively. The resulting frequency modes are labelled mode 19 and mode 13. A tunable Martin-Pupplet interferometer is used for single sideband (SSB) filtering. Pre-flight measurements show a nominal sideband suppression of better than $19 \mathrm{~dB}$ across the image band, with a maximum suppression of $35 \mathrm{~dB}$ (Eriksson et al., 2002a). However, post-launch analysis of spectra indicates that the true suppression rather is $11-15 \mathrm{~dB}$ for the frequency modes used in this study.

The spectra are recorded using one of the two autocorrelator spectrometers among the SMR backends. Each autocorrelator has four sub-bands of $200 \mathrm{MHz}$, and provides a total bandwidth of $800 \mathrm{MHz}$. For mesospheric studies of the $557 \mathrm{GHz}$ line only a part of full bandwidth is needed, and just the $200 \mathrm{MHz}$ sub-band covering the line is used in the re- 
trieval process. The effective channel resolution of the spectrometer is $2 \mathrm{MHz}$, and the channel separation $1 \mathrm{MHz}$. Furthermore, post-launch analysis of the instrument has revealed that the autocorrelators have problem measuring spectra with large dynamic ranges, i.e. large differences in brightness temperature across the bandwidth of the instrument. This results in a low bias in the recorded brightness temperature, which becomes especially apparent in high-altitude measurements (Lossow et al., 2007). To compensate for this, the measured spectra in this study are scaled by 1.03 before they are inverted.

The amount of noise in each channel is determined by the noise temperature of the system, the effective channel resolution, and the integration time. For the frequency bands used in this study, SMR has a noise temperature of roughly $3000-3500 \mathrm{~K}$. For the tomographic mode measurements, an integration time of $1.8 \mathrm{~s}$ is used. Due to the time used switching between calibration measurements and atmospheric measurements, SMR is only measuring the atmosphere about half of the total time. Taking this into account, the resulting thermal noise $(1 \sigma)$ is of the order of $2.6 \mathrm{~K}$ for the measured spectra.

To relate the measured radiation to a physical brightness temperature a calibration must be performed. The SMR measurements are calibrated by switching between the cold sky (space) and the atmosphere, with a hot-load calibration performed at the end of each scan. In this study the newest version (V8) of the calibrated Odin spectra is used. This version was prepared during the autumn of 2013, and beside improving the treatment of known instrumental artefacts, it corrected an error related to the transition between orbits, which previously had made the tomographic observations unusable.

The vertical resolution of the measurements depends on the size and shape of the antenna pattern. For SMR the antenna is a $1.1 \mathrm{~m}$ Georgian telescope which provides a halfpower beam width better than $0.035^{\circ}$ (Frisk et al., 2003). This results in a vertical resolution at the tangent point of $\sim 1.6 \mathrm{~km}$. However, due to the telescope continuously scanning vertically during the integration time of $1.8 \mathrm{~s}$ the angular resolution is reduced to $0.04^{\circ}(\sim 1.8 \mathrm{~km})$ in the tomographic mode.

\subsection{OSIRIS}

In addition to presenting the results from the SMR tomographic mode retrievals, this paper also includes some comparisons with the PMC brightness retrieved from the optical spectrograph of OSIRIS. The spectrograph is a modified Erbert-Fastie grating spectrometer with a CCD backend, and can measure light scattered from the atmosphere between 280 and $800 \mathrm{~nm}$ with a spectral resolution of around $1 \mathrm{~nm}$. The entrance slit of OSIRIS is aligned parallel to the horizon, and subtends a region $30 \mathrm{~km}$ wide and $1 \mathrm{~km}$ high at the tangent point.
To retrieve PMC properties from the scattered light, the measured radiation in the wavelength region of 302.8 to $305.9 \mathrm{~nm}$ is compared to a purely Rayleigh scattering background field calculated using the MSIS climatology. The differences between the measured and simulated spectra are then used as inputs to a tomographic retrieval scheme based on a modified version of the Multiplicative Algebraic Reconstruction Technique (MART, Degenstein et al., 2003). The retrievals return the scattering coefficient of the clouds with a $330 \mathrm{~km}$ horizontal resolution and $1 \mathrm{~km}$ vertical resolution, and an accuracy of $4 \times 10^{-11} \mathrm{~m}^{-1} \mathrm{str}^{-1}$. For a detailed description of the observations and retrieval process the reader is referred to Hultgren et al. (2013).

\section{Retrieval methodology}

To extract atmospheric data from the SMR measurements the optimal estimation method (OEM) is applied. ARTS (Atmospheric Radiative Transfer Simulator) is used as the forward model, and the retrieval procedure is implemented using a software package accompanying ARTS. As previously mentioned, the overlapping lines-of-sight for the measurements allows for a tomographic retrieval approach. This means that a 2-D map of the atmospheric fields is retrieved, rather than single vertical profiles. The following section describes the forward model and retrieval procedure used in this study.

\subsection{Forward model}

\subsubsection{General about ARTS}

ARTS is a general purpose radiative transfer program, with a focus on supporting passive microwave sounding techniques (Buehler et al., 2005). It is publicly available software. The second version of ARTS (Eriksson et al., 2011) allows simulations for 1-D, 2-D or 3-D atmospheres, where the 2-D option is applied in this study. ARTS uses pressure as the main vertical coordinate. For 2-D, the observations are assumed to be performed along the orbit plane, and the horizontal coordinate can be seen as the angle along the orbit (AAO). For a hypothetical satellite having an orbit inclination of $90^{\circ}$, the AAO could be set to match the geocentric latitude between $-90^{\circ}$ and $+90^{\circ}$, but ARTS allows the AAO to extend outside this range and the AAO zero point is a user choice.

The main difference between 1-D, 2-D and 3-D calculations is the ray tracing - the actual (clear-sky) radiative transfer is solved identically in all three cases. That is, after the atmospheric quantities along the propagation path are determined, the radiative transfer along the path can be handled independently of the atmospheric dimensionality. The treatment of weighting functions (columns of the Jacobian matrix) can be handled in basically the same way, and ARTS provides these functions for the same set of atmospheric 
quantities for 1-D, 2-D and 3-D. Atmospheric weighting functions are calculated using analytical expressions (ARTS also provides a pure numerical option), but these consider only local effects. For example, for temperature the hydrostatic equilibrium around each separate height is taken into account, but not how the hydrostatic adjustment propagates to other altitudes. Furthermore, refraction is ignored in this study, as the effects are negligible for measurements limited to the mesosphere.

\subsubsection{Grids}

The forward model atmosphere has a vertical grid stretching from $13.33 \mathrm{hPa}(\sim 30 \mathrm{~km})$ to $42 \mu \mathrm{Pa}(\sim 150 \mathrm{~km})$. The grid has an altitude spacing of $100 \mathrm{~m}$ between $2.94 \mathrm{hPa}(\sim 40 \mathrm{~km})$ and $0.18 \mathrm{mPa}(\sim 140 \mathrm{~km})$, while above and below a spacing of 250 and $500 \mathrm{~m}$ is used, respectively. This dense vertical spacing is needed to accurately simulate the radiation from the saturated water vapour line around the mesopause, where strong vertical gradients are found.

The horizontal AAO grid used in the forward model starts when the satellite crosses the equator $\left(\mathrm{AAO}=0^{\circ}\right)$ and covers the Northern Hemisphere from AAO 30 to $150^{\circ}$. However, since the matrices used in the tomographic retrieval approach (see Sect. 3.2) generally are non-sparse, an entire orbit cannot be processed simultaneously on a desktop computer (32 GB RAM) unless some data reduction technique such as binning channels together or eigenvector expansion of the Jacobian matrix (Eriksson et al., 2002b) is applied. To keep the processing scheme simple, we have chosen not to apply any such techniques, but following Livesey et al. (2006) we instead split the measurements into "batches" of 12 scans ( $\sim 150$ spectra) covering $\sim 40^{\circ}$ AAO (see Fig. 1). This results in that the forward model horizontal grid for each batch covers $\pm 30^{\circ}$ AAO $(\sim 4500 \mathrm{~km})$ around the centre of the batch, with a spacing of $0.25^{\circ}(\sim 30 \mathrm{~km})$. Outside this area, 16 additional grid points cover the AAOs up to $\pm 50^{\circ}$ AAO with a lower spacing to ensure that no errors arise from edge effects.

\subsubsection{Frequency grid and line parameters}

ARTS is a line-by-line radiative transfer simulator, and for simulation of the $556.9 \mathrm{GHz}$ water vapour transition we use a monochromatic frequency grid ranging from 556.5 to $557.5 \mathrm{GHz}$. The spacing is $100 \mathrm{kHz}$ around the line centre $(556.925-556.945 \mathrm{GHz})$ decreasing further away from the line centre reaching $100 \mathrm{MHz}$ at the far end of the grid. In addition to the frequencies in the signal band, some frequencies are added in the image band to accurately take into account influence of the sideband filtering. For the simulations in this study involving just a handful of transitions, absorption is best calculated for each point along the propagation paths ("on the fly" in ARTS terminology), as the option of using a pre-calculated look-up table is slower.
The line parameters for the water vapour line are taken from the JPL and HITRAN2012 databases. JPL (Pickett et al., 1998) is used for the line position $(556.9359877 \mathrm{GHz})$ and the line strength $\left(229.8489 \mathrm{~Hz} \mathrm{~m}^{-2}\right)$. HITRAN 2012 (Rothman et al., 2013) is used for the pressure broadening coefficient $\gamma_{\mathrm{p}}$. The coefficient is calculated as $\gamma_{\mathrm{p}}(p, T)=$ $p \gamma_{\text {air }}\left(T / T_{0}\right)^{n}$, where $\gamma_{\text {air }}=31362.45 \mathrm{HzPa}^{-1}$ is the pressure broadening parameter, $T$ the atmospheric temperature, $T_{0}=296 \mathrm{~K}$ the reference temperature for the broadening parameters, and $n=0.75$ the exponent of the temperature dependency.

\subsubsection{Instrument parameters}

ARTS includes extensive support for incorporating instruments characteristics. Using the methodology introduced by Eriksson et al. (2002a, 2006), monochromatic pencil beam spectra are combined, taking into account the response of antenna, mixer sidebands and spectrometer, to simulate final sensor brightness temperatures. For this study, the modelled antenna pattern is based on the measurements of the SMR antenna system, the single sideband filter is modelled as a flat function with a sideband suppression of $14 \mathrm{~dB}$, and the spectrometer backend channel response is based on a theoretical model of the spectrometer.

\subsection{Retrieval}

\subsubsection{General OEM}

In the optimal estimation method the retrieved state vector, $\hat{\boldsymbol{x}}$, is the one minimising the a posteriori error, based on the known, or assumed, properties of the variations of the atmosphere and errors in the observation (Rodgers, 2000). Due to the non-linearity of the retrievals in this study an iterative Levenberg-Marquardt method is applied. The state vector of iteration $i+1$ from the OEM method is then given by

$$
\begin{aligned}
\hat{\boldsymbol{x}}_{i+1}= & \hat{\boldsymbol{x}}_{i}+\left[(1+\gamma) \mathbf{S}_{\mathrm{a}}^{-1}+\left(\mathbf{K}_{i}^{\mathrm{T}} \mathbf{S}_{\epsilon}^{-1} \mathbf{K}_{i}\right)\right]^{-1} \\
& {\left[\mathbf{K}_{i}^{\mathrm{T}} \mathbf{S}_{\epsilon}^{-1}\left(\boldsymbol{y}-f\left(\boldsymbol{x}_{i}\right)\right)-\mathbf{S}_{\mathrm{a}}^{-1}\left(\boldsymbol{x}_{i}-\boldsymbol{x}_{\mathrm{a}}\right)\right], }
\end{aligned}
$$

where $\mathbf{S}_{\mathrm{a}}$ and $\mathbf{S}_{\epsilon}$ are the covariance matrices for the a priori state vector, $\boldsymbol{x}_{\mathrm{a}}$, and the thermal noise in the measurement given by $\boldsymbol{y}, \mathbf{K}_{i}$ is the Jacobian matrix calculated using the forward model of iteration $i, f\left(\boldsymbol{x}_{i}\right)$, and $\gamma$ is the LevenbergMarquardt parameter. It is adjusted after each iteration based on whether the cost function to be minimised is decreased or increased by the iteration. For the first iteration $\boldsymbol{x}_{1}=\boldsymbol{x}_{\mathrm{a}}$ and $\gamma=500$. For each successful iteration $\gamma$ is divided by 10 , and for each failed iteration it is doubled. Convergence is reached when the change in the retrieved state vectors between iterations, normalised by the retrieved covariance, is less than 0.0001 times the length of the state vector, $n$, i.e.

$$
\left(\hat{\boldsymbol{x}}_{i}-\hat{\boldsymbol{x}}_{i+1}\right)^{\mathrm{T}}\left[\mathbf{S}_{\mathrm{a}}^{-1}+\left(\mathbf{K}_{i}^{\mathrm{T}} \mathbf{S}_{\epsilon}^{-1} \mathbf{K}_{i}\right)\right]\left(\hat{\boldsymbol{x}}_{i}-\hat{\boldsymbol{x}}_{i+1}\right)<0.0001 \cdot n .
$$


In most cases this is achieved after 7-10 iterations, and the final normalised costs are between $0.9-1.1$ for $95 \%$ of the retrieved batches. The convergence criterion was tested by running the retrievals with a higher convergence threshold $\left(n \times 10^{-6}\right)$, and ensuring that the differences between the results with a high and low threshold were sufficiently small (less than 0.05 ppmv for $\mathrm{H}_{2} \mathrm{O}$ and $0.2 \mathrm{~K}$ for temperature).

Of all the retrieved batches, about $30 \%$ have a final iteration where the ML-parameter increases to 1 after several iterations with a parameter of 0 (and another $2 \%$ where it increases above one). A final $\gamma$ greater than one might imply that the retrievals converged before finding the local minimum of the cost function. To ensure that the solution found in these cases do not differ significantly from the true minimum, the decrease in total cost for the iterations prior (i.e. where $\gamma=0$ ) is analysed, and if changes in normalised cost between these iterations are sufficiently small $(\sim 0.01)$, we regard the solution as valid.

\subsubsection{The state vector}

The state vector contains all the variables to be retrieved, and in this study the state vector consists of the logarithm of atmospheric water vapour relative to the a priori $\left(\boldsymbol{H}_{2} \boldsymbol{O}\right)$, atmospheric temperatures in Kelvin $(\boldsymbol{T})$ and some instrument variables. These variables are a baseline fit, a frequency shift and a fit of the pointing error. The instrumental baseline arises due to standing waves in the receiver, and to fit this, a firstorder polynomial is fitted to each spectrum $\left(\boldsymbol{P}_{\mathbf{0}}, \boldsymbol{P}_{\mathbf{1}}\right)$. The exact positioning of the LO frequency has some uncertainty. This is fitted with a single-frequency fit $(\Delta F)$ across each batch. Finally, there is an uncertainty in the pointing of the antenna, and a single pointing offset $(\Delta \theta)$ is retrieved across the batch.

The total state vector is given by combining all the subvectors:

$\boldsymbol{x}=\left[\boldsymbol{H}_{\mathbf{2}} \boldsymbol{O}, \boldsymbol{T}, \Delta F, \Delta \theta, \boldsymbol{P}_{\mathbf{0}}, \boldsymbol{P}_{\mathbf{1}}\right]^{\mathrm{T}}$.

For the atmospheric fields $\left(\boldsymbol{H}_{\mathbf{2}} \boldsymbol{O}, \boldsymbol{T}\right)$ the elements are sorted first by altitude then by latitude and the retrieval grid covers altitudes between $316 \mathrm{~Pa}(\sim 40 \mathrm{~km})$ and $0.75 \mathrm{mPa}(\sim$ $130 \mathrm{~km})$ with an altitude spacing of $1 \mathrm{~km}$ above $17 \mathrm{~Pa}(\sim$ $60 \mathrm{~km}$ ) and a spacing of $2 \mathrm{~km}$ below. The horizontal retrieval grid covers $50^{\circ}$ AAO centred around the batch with a spacing of $0.5^{\circ}$. For both the forward model and retrieval grid the values are treated to vary linearly between the grid points (Buehler et al., 2005), thus effectively, a bilinear interpolation is applied to convert between the two grids.

\subsubsection{A priori values}

For each state vector variable an a priori value must be given. For the atmospheric variables, these are given as 2-D fields

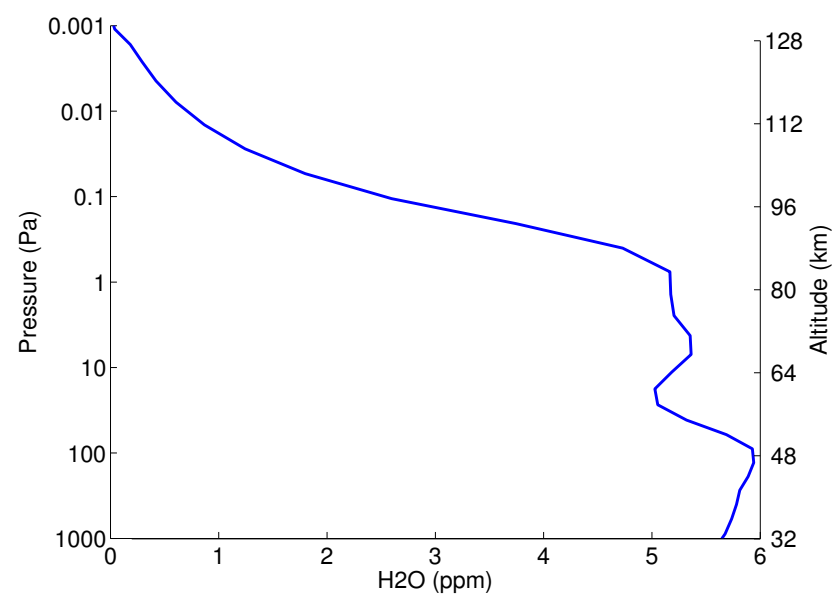

Figure 2. The $\mathrm{H}_{2} \mathrm{O}$ a priori profile created from the mean of a MLS climatology.

across the retrieval grid. For water vapour, an a priori profile constant with latitude and time was chosen. Using such a fixed a priori profile makes it easier to ensure that the structures seen in the retrieved water vapour field actually come from the measurements, rather than the a priori field. The a priori profile is based on a climatology of water vapour from the MLS instrument on board the Aura satellite. Taking the mean of the MLS water vapour concentrations from June, July and August for latitudes above $60^{\circ}$, the profile shown in Fig. 2 is obtained.

For temperature the MSISE-90 model (Hedin, 1991) is used as the a priori value. The model gives the mean temperature for each month as a function of latitude and pressure, covering pressures from $1013 \mathrm{hPa}(\sim 0 \mathrm{~km})$ to $5.7 \times$ $10^{-4} \mathrm{~Pa}(\sim 130 \mathrm{~km})$. Furthermore, the MSISE-90 climatology is used for the pressure-altitude relationship for the retrievals. However, since temperature, pressure and altitude are closely interlinked through hydrostatic equilibrium (HSE), the pressure-altitude relationship must be adjusted during the retrieval to ensure a consistent relationship between the three variables. This is done by using the MSISE-90 model to find the geometrical altitude corresponding to a pressure level of $2.9 \mathrm{~Pa}$, and the correcting the pressure-altitude relationship for the other pressure levels by assuming HSE in the retrieved atmosphere.

For the instrumental variables, the a priori assumption is that the measurements are correct, i.e. a value of 0 is used for the frequency shift, pointing error and the baseline fits.

\subsubsection{A priori covariance}

The optimal estimation method requires, in addition to a priori values, a covariance matrix to be created for the state vector variables. The total covariance matrix is set to a block diagonal matrix with the covariance matrix for each variable in 
(a) Horizontal covariance

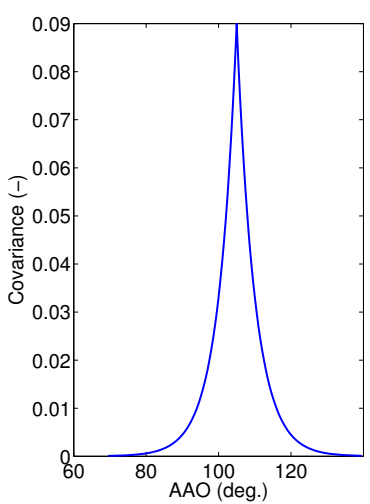

(b) Vertical covariance

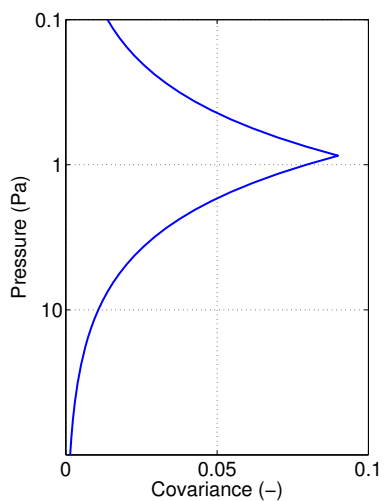

(c) $\mathrm{H} 2 \mathrm{O}$ covariance Matrix

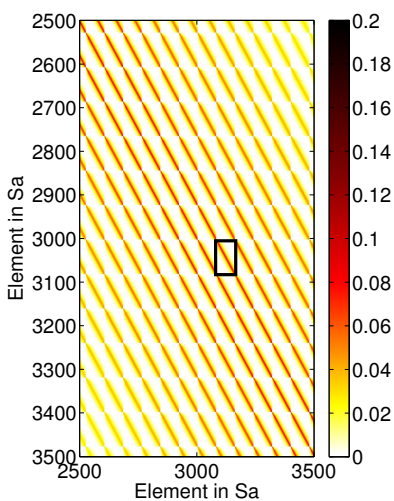

Figure 3. (a) Vertical and (b) horizontal elements of the covariance matrix for $\mathrm{H}_{2} \mathrm{O}$ at $\mathrm{AAO} 0.09 \mathrm{~Pa}$ and $105^{\circ}$. (c) Elements of the total covariance matrix for water vapour. The black square indicates a single covariance block, i.e. covariance between altitudes at the same AAO.

each block:

$\mathbf{S}_{\mathrm{a}}=\left(\begin{array}{cccccc}\mathbf{S}_{\mathrm{a}}^{\mathrm{H}_{2} \mathrm{O}} & 0 & 0 & 0 & 0 & 0 \\ 0 & \mathbf{S}_{\mathrm{a}}^{\mathrm{Temp}} & 0 & 0 & 0 & 0 \\ 0 & 0 & \left(\sigma_{\mathrm{a}}^{\Delta F}\right)^{2} & 0 & 0 & 0 \\ 0 & 0 & 0 & \left(\sigma_{\mathrm{a}}^{\Delta \theta}\right)^{2} & 0 & 0 \\ 0 & 0 & 0 & 0 & \mathbf{S}_{\mathrm{a}}^{P 0} & 0 \\ 0 & 0 & 0 & 0 & 0 & \mathbf{S}_{\mathrm{a}}^{P 1}\end{array}\right)$.

For the atmospheric fields the a priori covariance matrices are matrices with non-zero elements far from the diagonal due to correlation in the errors in the a priori atmosphere and natural variation across the 2-D grid. The standard deviation for the atmospheric fields are set to $30 \%$ for water vapour, and $7 \mathrm{~K}$ for temperature.

The spatial correlations are set using correlation functions in both the vertical and horizontal directions. The correlation is modelled as a function, $\rho$, decreasing exponentially with altitude/AAO. The correlation lengths, $l_{\mathrm{c}}$, defined by $\rho\left(l_{\mathrm{c}}\right)=\exp ^{-1}$, are specified to $5^{\circ}$ in the horizontal direction and $8 \mathrm{~km}$ in the vertical direction for both water vapour and temperature. These covariances represent the large-scale uncertainties of our a priori fields. However, some degree of ad hoc adjustments were made the to reduce possible vertical and horizontal oscillations in the retrieved data. The covariance for water vapour in the horizontal and vertical directions is shown in Fig. 3a and b.

The total correlation in both dimensions is calculated as

$\rho_{\text {tot }}=\exp ^{-\sqrt{\left(\frac{\Delta x}{l_{\mathrm{x}}}\right)^{2}+\left(\frac{\Delta y}{l_{\mathrm{y}}}\right)^{2}}}$,

where $\Delta x$ and $\Delta y$ is the distance between two points in the horizontal and vertical direction and $l_{\mathrm{x}}$ and $l_{\mathrm{y}}$ the corresponding correlation length. A part of the complete covariance matrix for water vapour is shown in Fig. 3a. It can be seen that the matrix has a block structure, where each block $\mathbf{S}_{\mathrm{a}}^{i, j}$, indicated by the black square in the figure, is the covariance matrix covering all altitudes at one AAO, and the off-diagonal blocks are the vertical covariance matrix multiplied by the correlation between the different AAOs.

For the instrumental variables the covariance matrices are pure diagonal matrices (or scalars). For the baseline polynomial fits the uncertainty is set to 4 and $2 \mathrm{~K}$ for the zeroth and first order respectively. For the frequency fit the covariance matrix is simply a scalar with an assumed uncertainty of $100 \mathrm{kHz}$, whereas for the pointing error the uncertainty is set to $0.001^{\circ}$. The strict constraint on the pointing offset is needed to prevent the non-linear retrievals from converging to unrealistic results.

\section{Results}

\subsection{A simulated case}

In order to illustrate the viability of the tomographic methodology, a simulated retrieval was performed. In this way the sensitivity of the retrievals to changes in water vapour and temperature can be investigated. The mean temperature and water vapour retrieved from the tomographic measurements was used as the atmospheric a priori in the simulation. Since the purpose of this study is to look at small-scale variations of water vapour and temperature around PMCs, a water vapour enhancement of $50 \%$ was simulated in three small regions of the atmosphere. One such region was centred at $79^{\circ} \mathrm{AAO}$ and $82 \mathrm{~km}$ in altitude. This region was given a size of $200 \mathrm{~km} \times 3 \mathrm{~km}$, which roughly corresponds to the estimated resolution of the tomographic measurements (see Sect. 5.1.1). A smaller region $(100 \mathrm{~km} \times 1 \mathrm{~km})$ was positioned at $\sim 74^{\circ} \mathrm{AAO}$, to test the limits of the method. Finally, a region with a small horizontal $(100 \mathrm{~km})$, but large vertical $(15 \mathrm{~km})$ extent was simulated at $\sim 67^{\circ}$ AAO to investigate 
(a)

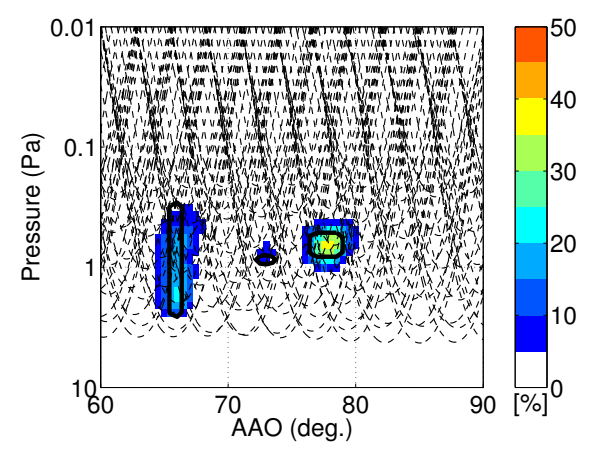

(b)

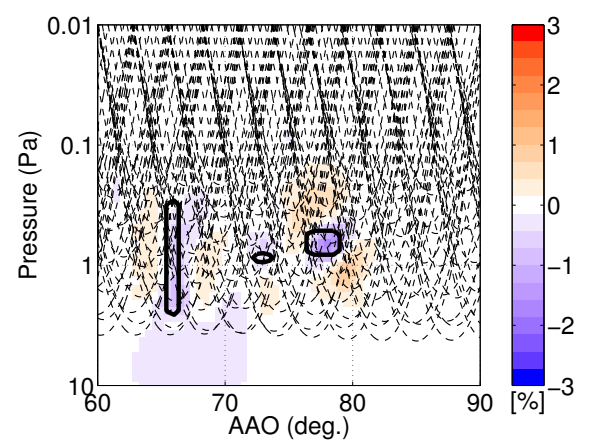

Figure 4. Water vapour (a) and temperature (b) from the tomographic retrievals where a $50 \%$ enhancement of water vapour is simulated in the areas marked by the black squares. The results are presented in terms of deviation from the a priori (\% and K). The dashed lines show the lines-of-sight of SMR.

the effect of horizontal inhomogeneities. Using this atmosphere, a set of simulated measurements was generated. This test atmosphere might not be realistic, but should be a useful tool for qualitatively evaluating the performance of the methodology. The retrieval was performed as described in Sect. 3. No noise was added to the simulated data, but the simulated retrievals were done using a noise covariance matrix describing a thermal noise with a $\sigma$ of $2.6 \mathrm{~K}$.

Figure 4a shows the retrieved water vapour, relative to the a priori atmosphere, from the simulated retrieval. The areas with enhanced water vapour are shown by the black contours, and the retrieved water vapour is shown by the colour of each pixel. Looking at the area around $79^{\circ}$ it is clear from the results that the retrievals can reproduce the water vapour enhancement, though some smoothing is seen. This smoothing is expected, as the enhanced area is of the same size as the $67 \%$ centred quantile resolution derived in Sect. 5.1.1.

The values retrieved for the enhanced area at $\sim 67^{\circ}$ show that inhomogeneities with an even smaller horizontal extent can be retrieved at the correct position. The vertical edges of the inhomogeneity are accurately reproduced by the retrievals. However, a large effect of the limited spatial resolution can be seen as the retrieved enhancement is around $15-25 \%$ rather than the true value of $50 \%$. This is also the case for the smallest area at $74^{\circ}$ AAO where an enhancement of less than $10 \%$ is retrieved. Thus, this small area of $100 \mathrm{~km} \times 1 \mathrm{~km}$ indicates the smallest regions of change we can expect our measurements to be sensitive to, although it should noted that retrieved values from such small areas in most cases will be overshadowed by the random variations from noise in the data.

In addition to water vapour, the tomographic retrieval returns the temperature field of the atmosphere. Due to the nature of the measurement method, the Jacobian matrix is not completely block diagonal with respect to the two atmospheric variables. This means that the two retrieved quantities will not be independent of each other. As a result an increase in water vapour will influence the retrieved temperature field. Figure $4 \mathrm{~b}$ shows the change in retrieved temperature due to the simulated water vapour enhancements, and variations of $\pm 1 \mathrm{~K}$ are seen in the retrieved data around the water vapour enhancements.

To test the temperature retrievals, another simulation was set up. In this simulation (not shown) the water vapour distribution was set equal to the measured mean, and the temperature was perturbed by reducing it by $10 \mathrm{~K}$ in the same manner as with the test simulation for water vapour. For the temperature the perturbed areas were reproduced in the correct position, but the retrieved values were up to $5 \mathrm{~K}$ warmer than the true value. The reason for this is that the temperature resolution, in particular the $95 \%$ quantile resolution, is worse than resolution of the retrieved water vapour, thus a larger smoothing effect is seen. For further discussion on this see Sect. 5.1.1. The influence that changes in temperature had on the retrieved water vapour field were up to $8 \%$ in the retrieved water vapour within the perturbed areas, and no change outside of them.

These simulated tests are not a complete validation of the retrievals, but meant to illustrate some of the capabilities and limitations of the method. The final test of the abilities of the measurements to estimate the true atmosphere will be done by comparing the retrieved data to other instruments. A further discussion of this along with possible sources of uncertainties and errors in the retrievals can be found in Sect. 5.

\subsubsection{Comparison to 1-D retrievals}

The simulated case also provides an opportunity to compare the tomographic retrieval method to a standard 1-D retrieval. In 1-D retrievals each scan through the atmosphere is retrieved independently. To ensure that the definitions and constraints of the 1-D retrievals are consistent with the tomographic approach the inversions were done using the same setup as described in Sect. 3, but with the state vector only 
(a)

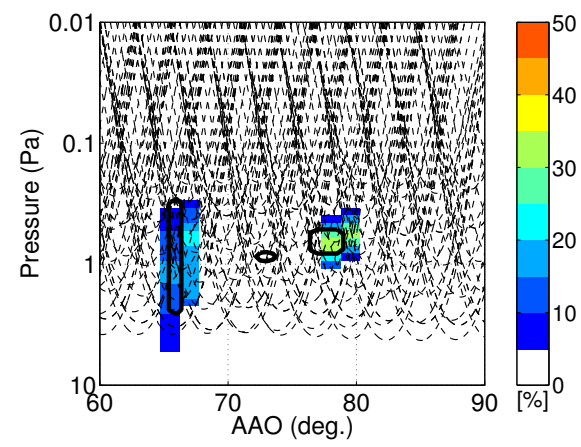

(b)

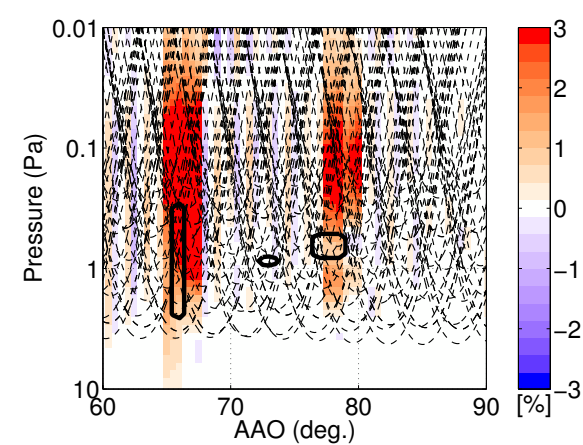

Figure 5. Water vapour (a) and temperature (b) from 1-D retrievals where a $50 \%$ enhancement of water vapour is simulated in the areas marked by the black squares. The results are presented in terms of deviation from the a priori (\% and K). The dashed lines show the lines-of-sight of SMR.

(a)

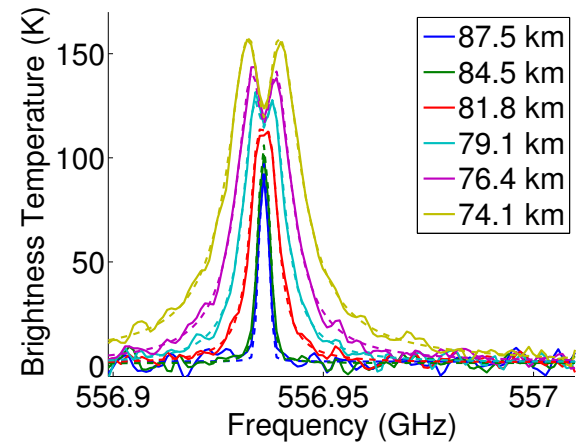

(b)

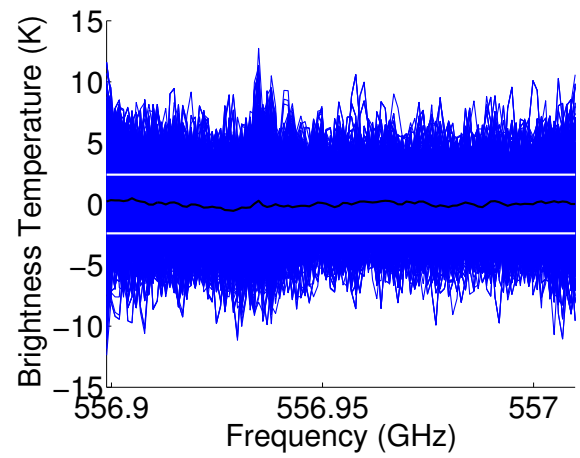

Figure 6. (a) Sample spectra of the $557 \mathrm{GHz}$ line from orbit 51226 at different heights (solid lines), with fitted spectra (dashed lines). (b) Residuals of all spectra in orbit 51226 (blue), mean of the residuals in that orbit (black) and the average $(1 \sigma)$ thermal noise of the measurements (white).

describing a single AAO centred at the mean tangent point of the scan (i.e. assuming horizontal homogeneity).

Figure 5 shows the retrieved water vapour and temperature using the 1-D retrieval method from the same test case as in Fig. 4. The 1-D method recreates the water vapour enhancements with reasonable accuracy, except for the smallest region, which is not detected. The position of the two regions at $67^{\circ}$ and $79^{\circ}$ is shifted away from the satellite. This shift occurs due to the sampling of the atmosphere, so depending on the position of the measurements in relation to the enhanced area, the shift might be both towards or away from the satellite. Furthermore, the lower edge of the area at $67^{\circ}$ is not successfully recreated in the 1-D retrievals.

For the retrieved temperature field, the differences between the tomographic and 1-D methods are larger. Large areas of increased temperatures can be seen at the latitudes of the water vapour enhancements. These temperature errors arise since some measurements have a line-of-sight going through the perturbed area, but not at the tangent point. For these measurements the 1-D method will misplace perturba- tion by several kilometres in altitude and AAO. Since the purpose of the tomographic measurements is to study the atmosphere around polar mesospheric clouds, an area where large horizontal variations in water vapour can be expected, the demonstrated temperature and water vapour artefacts seen in the 1-D approach would significantly degrade the data, and thus a tomographic retrieval approach is preferred for these measurements.

\subsection{Result from a real case}

To exemplify the results of the tomographic measurements, two orbits (51221 and 51226) recorded on 15 July 2010 are selected as example orbits. Orbit 51221 is selected as collocations between Odin-SMR and both ACE-FTS and AIMSOFIE can be found along this orbit. Orbit 51226 is used since it is an orbit recorded soon after, where SMR is using the other frontend.

Figure 6 shows some example spectra from orbit 51226 at different tangent altitudes. The saturation of the line at the 

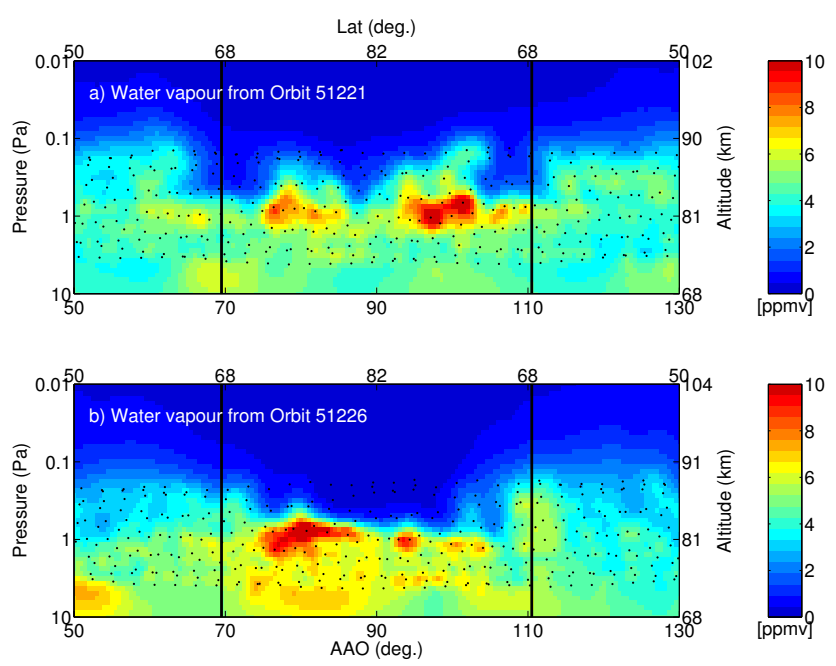

Figure 7. Example results from orbit 51221 and orbit 51226 on 15 July 2010. The lower $x$-axis shows the AAO and the top axis shows the true latitude of the measurements. The black lines indicate the positions of collocated ACE-FTS and AIM-SOFIE measurements. The black dots are the tangent position for each measurement.

lower altitudes is seen, as the brightness temperature of the line centre is lower than the line wings, reflecting the negative temperature gradient of the mesosphere. The spectra fitted by the retrievals are shown as dashed lines showing how they reproduce the general shape and amplitude of the measured spectra. To get a better view of the fit, the residuals from all spectra in orbit 51226 are shown in Fig. 6b. Ideally the residuals should be white noise with a standard deviation equal to that of the thermal noise of the receiver. For most of the spectrometer channels this is true; however, for the channels closest to the line centre some non-white noise can be seen in single measurements.

\subsubsection{Water vapour and temperature}

Figure 7 shows the retrieved water vapour for the two selected orbits. The retrieved fields cover latitudes (top $x$-axis) from $\sim 50$ up to $82^{\circ} \mathrm{N}$ and then down to $\sim 50^{\circ} \mathrm{N}$ on the other side of the pole. The approximate altitudes for the pressure levels are given on the right $y$-axis. These are found by taking the mean altitude of each pressure level across the orbit. The vertical distribution of water vapour shows high concentration ( $>4 \mathrm{ppmv}$ ) up to $\sim 85 \mathrm{~km}$ where it quickly drops down to values between 0 and 2 ppmv. This is consistent with the current understanding of the dynamics of the summer mesosphere where water vapour is brought up from the lower altitudes by the mesospheric overturning circulation and removed by photodissociation as it reaches the mesopause.

The latitudinal distribution of water vapour shows generally higher concentrations towards the pole than at lower latitudes, and both orbits have large areas with water vapour

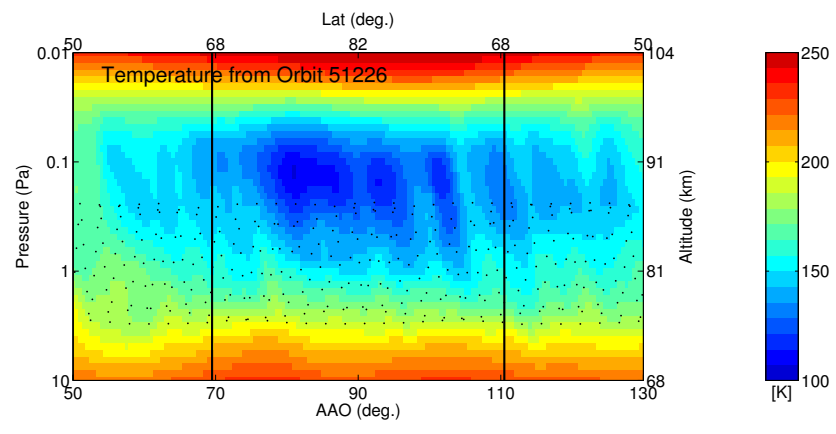

Figure 8. Temperature retrieved from orbit 51226 on 15 July 2010. The lower $x$-axis shows the AAO and the top axis shows the true latitude of the measurements. The black lines indicate the positions of collocated ACE-FTS and AIM-SOFIE measurements. The black dots are the tangent position for each measurement.

concentrations above 10 ppmv between 70 and $80^{\circ} \mathrm{N}$. Figure $7 \mathrm{~b}$ in particular shows high amounts of water vapour in two areas at 80 and $100^{\circ} \mathrm{AAO}$, while in Fig. 7a the concentration is highest at $80^{\circ} \mathrm{AAO}$. These areas arise as a result of atmospheric dynamics combined with the redistribution of water vapour due to the presence of PMCs.

Below $80 \mathrm{~km}$ there are significant differences between the two orbits. Figure $7 \mathrm{~b}$ shows less water vapour overall, and large amount of water between 70 and $100^{\circ} \mathrm{AAO}$ is not present compared to Fig. 7a. Comparing several other orbits shows that this is probably due to instrumental differences between the two frontends rather than a physical change in the real atmosphere. The consequences and implication of this will be elaborated further in Sect. 5.3, where the results are compared to other satellite instruments.

The black dots in Figs. 7 and 8 show the positions of the tangent points for each measurements. At these points the contribution from the measurements should be the largest. A retrieval grid point between these dots may suffer from a high a priori contribution, depending on the exact position relative to the lines-of-sight of the measurements. This can lead to oscillatory structures in the data if there is a systematic difference between the true atmosphere and the a priori value. Looking at the results from the two test orbits, tendencies of such patterns are seen at the lower edge of the covered area $(75-80 \mathrm{~km})$, but in general the results should not be influenced by the sampling of the atmosphere.

Figure 8 shows the temperature field retrieved from orbit 51226. The retrieved temperature has a mesopause altitude around $90 \mathrm{~km}$ with the lowest mesopause temperatures $(\sim 115 \mathrm{~K})$ closest to the poles. This is once again due to the mesospheric overturning circulation, with the faster ascending air over the pole causing a stronger cooling than at lower latitudes. 

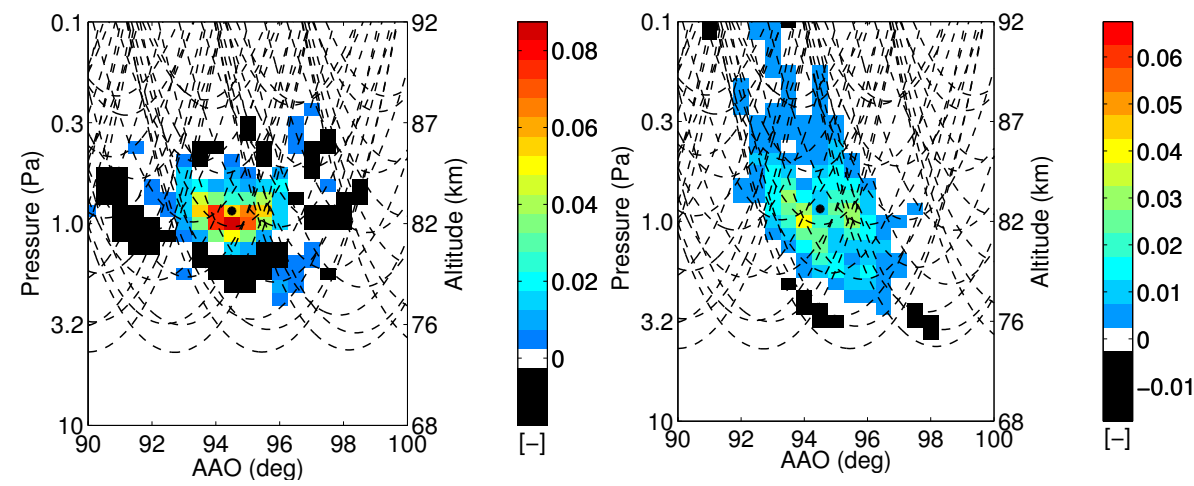

Figure 9. The 2-D averaging kernel of water vapour (left) and temperature (right) for the retrieval grid point marked by the black dot. The dashed lines show the line-of-sight of the measurements through the atmosphere.

\section{Discussion}

\section{$5.1 \quad$ 2-D averaging kernels}

Spatial resolution of retrieved data is usually described by the rows of the averaging kernel matrix (AKM), A. Each element in this matrix, $\mathbf{A}_{i j}$, gives the change in the retrieved state vector element $\hat{\boldsymbol{x}}_{\boldsymbol{i}}$ from a change in the true state vector element $\boldsymbol{x}_{j}$. We calculate the AKM by assuming that the final step in the Levenberg-Marquardt iteration has a LevenbergMarquardt parameter of 0 , i.e.

$\mathbf{A}=\left[\mathbf{S}_{\mathrm{a}}^{-1}+\left(\mathbf{K}^{\mathrm{T}} \mathbf{S}_{\epsilon}^{-1} \mathbf{K}\right)\right]^{-1} \mathbf{K}^{\mathrm{T}} \mathbf{S}_{\epsilon}^{-1} \mathbf{K}$

Note that for these batches where the final ML-parameter differs from zero, $\mathbf{A}$ is still calculated with an ML-parameter of 0 (i.e using Eq. 6). The reason for this is that the final solution (and hence the AVK) is independent of $\gamma$ (for further discussion see e.g. Ceccherini and Ridolfi, 2010 and the discussion thereof, and Raspollini et al., 2013).

For non-linear retrievals $\mathbf{A}$ will depend on the atmospheric state, and will vary between measurements. Thus, in order to give the most representative picture of the capabilities and limitation of the retrievals, we have chosen to show the averaging kernels calculated using the mean retrieved state from all the measurements in this paper.

The plots in Fig. 9 show a single row of the AKM, separated into the columns covering water vapour and temperature respectively. This row can be referred to as the 2-D averaging kernel (AVK), for the retrieval point considered (positioned at $94.5^{\circ} \mathrm{AAO}$ and $82 \mathrm{~km}$ altitude).

The 2-D averaging kernel for water vapour is relatively symmetric around the retrieval point. However, since this point is not placed directly in a line of sight, all contributions to the retrieved value will come from measurements of the adjacent grid points, thus the peak of the AVK will not be in the centre. We have chosen this point to illustrate a "worst case" scenario for the analysis of the averaging kernels. For retrieval grid points where several lines of sight intersect, the 2-D averaging kernels have their peak at the grid point.

Just as for water vapour, the temperature averaging kernel has peaks located at the measurement points surrounding the retrieval point, rather than at the retrieval point. Additionally the temperature AVK displays an asymmetry, weighting the information along the line of sight more than information from adjacent scans. If the centroid (first moment) position is calculated it is still placed at the retrieval point.

\subsubsection{Spatial resolution}

Although the averaging kernel matrix gives the most complete picture of where the retrieved information at each retrieval point comes from, it is still useful to define a resolution for the retrievals. To do this we first define the horizontal and vertical averaging kernel for a retrieval point as the sum of the 2-D averaging kernel for that point over all columns corresponding to a certain pressure (for the vertical averaging kernel) or AAO (for the horizontal averaging kernel). Thus the vertical averaging kernel for a retrieval point gives the total contribution from different altitudes to the retrieved value at the retrieval point. Similarly the horizontal averaging kernel gives the total contribution of each AAO to the retrieved value at the retrieval point.

From this definition an estimation of the horizontal and vertical resolution can be made. Since the 2 -D averaging kernels have multiple peaks, we use a definition of resolution based on the area under the horizontal and vertical AVKs. Following von Clarmann (2009) we use the centred quantile distance as a measure of resolution. However, due to possible negative sidelobes seen in the vertical and horizontal AVKs, we perform the quantile integral outwards from the centroid (first moment) position of corresponding averaging kernel, and not from the beginning of the horizontal/vertical grid. We thus define the two quantile resolutions (67 and 95\%) as the shortest distance between two points $p_{1}, p_{2}$ at the ordinate of the horizontal or vertical averaging kernel determined such that the area under the curve between $p_{1}$ and $p_{2}$ corre- 
(a)

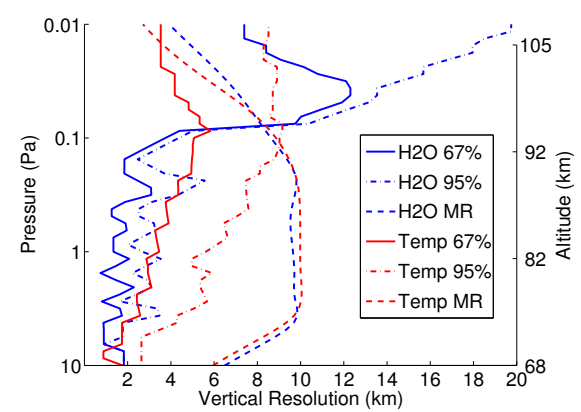

(b)

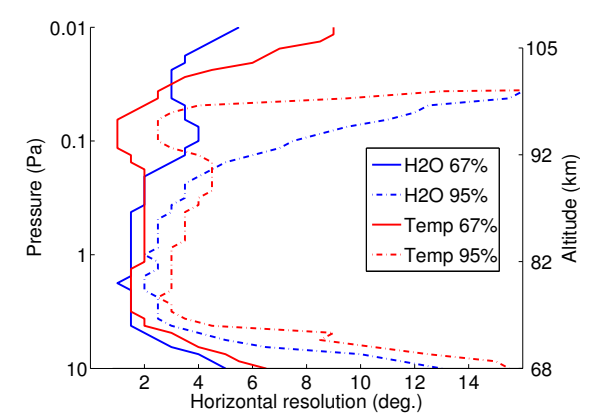

Figure 10. The estimated vertical (a) and horizontal (b) resolution for water vapour (blue) and temperature (red). The solid lines and dashdotted lines show the resolution calculated using the 67 and $95 \%$ quantiles, respectively. The dashed lines in (a) indicate the measurement response multiplied by 10 .

sponds to 67 or $95 \%$ of the total area under the horizontal or vertical averaging kernel.

Figure 10a and b show the estimated 67 and $95 \%$ vertical and horizontal resolution for temperature and water vapour for each altitude at $84^{\circ} \mathrm{AAO}$. For water vapour the vertical resolution $(67 \%)$ is between 1 and $2 \mathrm{~km}$ for the region of interest in this study $(75-90 \mathrm{~km})$. For temperature the vertical resolution $(67 \%)$ deteriorates for higher altitudes being $\sim 3 \mathrm{~km}$ at $80 \mathrm{~km}$ increasing to around $5 \mathrm{~km}$ at $90 \mathrm{~km}$. The horizontal resolution for water vapour and temperature is $1.8-2^{\circ}(\sim 200 \mathrm{~km})$ between 75 and $87 \mathrm{~km}$. The $95 \%$ resolutions are roughly a factor 2 worse. This leads to particularly poor resolutions at around $90 \mathrm{~km}$, indicating that a large degree of smoothing should be expected in this area.

\subsubsection{Measurement response}

The measurement response (MR) of the retrievals gives an indication of how sensitive the retrievals are to large-scale changes in the true atmosphere, and is calculated by summing the AVKs along each row over all columns corresponding to the retrieved variable (Baron et al., 2002). The measurement response for water vapour and temperature are shown by the dashed lines in Fig. 10. For both temperature and water vapour a response larger than 0.9 can be seen for the entire area of interest $(75-90 \mathrm{~km})$.

\subsection{Errors}

There are several possible sources of errors in the retrievals. Random errors come from thermal noise in the measurements (retrieval noise), from the limited resolution of the measurements (smoothing error), and pointing error in the satellite. Additionally, the results have systematic errors related to uncertainties in modelling of the instrument, modelling of the atmosphere, and uncertainties in the spectral line parameters. Just as with the averaging kernels, the effect of uncertainties and errors will depend on the true atmospheric profile. Thus, to give an indication of the average error ex- pected in the retrievals, the error analysis is based around a case linearised around the mean retrieved state of the measurements.

The smoothing error and retrieval noise can be calculated using the covariance matrices, $\mathbf{S}_{\mathrm{a}}$ and $\mathbf{S}_{\epsilon}$ respectively, as described in Rodgers (2000). The retrieval noise for the measurements presented in this study is $\sim 0.2 \mathrm{ppmv}$ for water vapour and $2-3 \mathrm{~K}$ for temperature. It should be noted that the errors arising from thermal noise in the data will be correlated in both the vertical and horizontal direction. From investigation of the retrieval noise covariance matrix, the correlation length of the retrieval noise is $2-3 \mathrm{~km}$ in altitude and $2-3^{\circ}$ in angle along orbit for both temperature and water vapour from 75 to $90 \mathrm{~km}$. An accurate estimation of the smoothing error requires that the atmospheric covariance matrix is known with certainty, which is not the case for these retrievals. As such we will not use the smoothing errors for the error analysis, but rather consider the retrieved result as the smoothed version of the true atmosphere, with a resolution given by the averaging kernels.

For the systematic errors, their influence is estimated by performing a simulated retrieval on the mean retrieved state with the forward model perturbed to the $\pm 1 \sigma$ estimate of the investigated parameter. The parameters investigated are the line strength $I_{0}$, which is perturbed $\pm 2 \%$, based on the JPL uncertainty, and the pressure broadening parameter $\gamma$, which is perturbed $5 \%$, based on differences between the measurements reported in Seta et al. (2008). Errors in the altitude of the HSE reference pressure level (2.9 Pa), Pressure, are estimated by moving the pressure level $\pm 2 \mathrm{~km}$, based on differences between MSISE-90 and CIRA86 (Fleming et al., 1990) at $70 \mathrm{~km}$. Additionally uncertainties related to the properties of the SMR instrument are simulated. The instrumental parameters investigated are an offset in the pointing of $\pm 0.02^{\circ}$ (Lossow et al., 2007), and uncertainties in the sideband suppression of $\pm 2 \%$ (11-15dB).

It should be noted that the presence of PMCs will not affect the retrieval of water vapour and temperature from SMR. The 
(a)

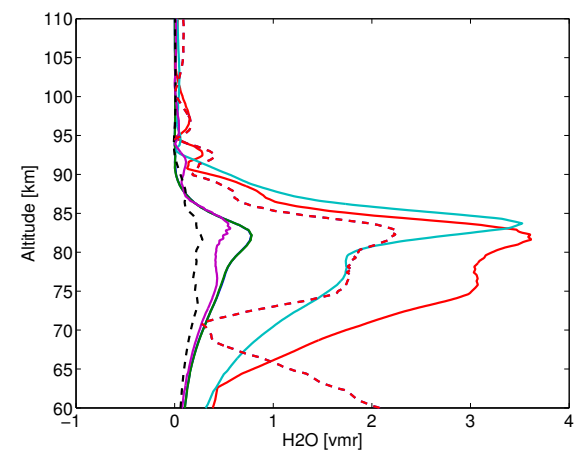

(b)

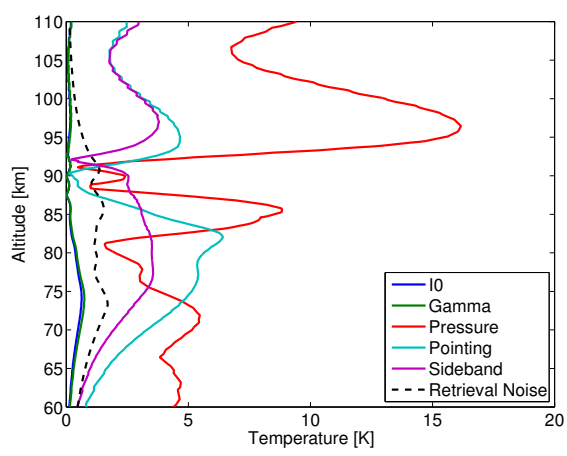

Figure 11. Estimated uncertainties for water vapour (a) and temperature (b) from the tomographic retrievals. The dashed black line shows the estimated retrieval noise. The solid lines show the errors due to forward model parameters. Finally, the dashed red line shows the uncertainty arising from errors in the background pressure, if number densities are used as the retrieved quantity. For a complete description of the parameters see the text.

radiance emitted from ice particles is of the order of $0.1 \mathrm{~K}$, and will be very uniform across the bandwidth of the spectrometer. As such, it will be completely overshadowed by any baseline in spectrometer, and thus corrected for in the polynomial baseline fit performed on each spectrum.

Figure 11 shows the random and systematic errors estimated around the mean atmospheric state. The plotted value, $\Delta E$, is the mean absolute value of the difference between the perturbed, $\boldsymbol{x}( \pm \sigma)$, and unperturbed, $\boldsymbol{x}(0)$, retrievals given by

$\Delta E=\frac{|\boldsymbol{x}(\sigma)-\boldsymbol{x}(0)|+|\boldsymbol{x}(-\sigma)-\boldsymbol{x}(0)|}{2}$.

The two largest sources of uncertainties in the retrievals are the pressure-altitude relationship (red line) and errors in pointing of the satellite (cyan line). The reason for this is that the weighting function for a change in water vapour is similar to the weighting function from the changing of the pointing angle of the satellite, or from a change in ambient pressure at different altitudes. Since the water vapour line is dominated by Doppler (compared to pressure-) broadening at the observed altitudes, and the number density of molecules decrease exponentially with altitude, any pointing error (or errors in altitude of the HSE reference point) will give rise to a large-scale change in the retrieved water vapour mixing ratio, and vice versa. The errors arising from assuming the wrong altitude of the 2.9 Pa pressure level can be adjusted for by ensuring that comparisons to other instruments or models are done with respect to a common pressure vs. altitude profile, in effect comparing number density- rather than mixing ratio profiles. If this is done, the estimated systematic error from this uncertainty is lowered to $\sim 2 \mathrm{ppmv}$ (red-dashed curve in Fig. 11).

The uncertainties from the two aforementioned errors (Pointing and Pressure) are however highly correlated across each orbit and will mainly affect the mean water vapour field retrieved in each orbit, and not the variations around this field. For these variations the other systematic errors will dominate, and these are of the order of $0.5 \mathrm{ppmv}$. Thus the measurements can reliably retrieve small-scale variations, despite the poor accuracy of the mean field. It should also be noted that the systematic errors introduced from the pointing and pressure uncertainties do not necessarily lead to a bias as both errors may vary across the measurement period.

\subsection{Comparison with other measurements}

As a final test of the ability of the observations to retrieve water vapour and temperature, the results are compared to measurements from other satellite instruments. The solar occulting instruments Atmospheric Chemistry Experiment-Fourier Transform Spectrometer (ACE-FTS) on board the SCISAT satellite (Bernath et al., 2005) and Solar Occultation for Ice Experiment (SOFIE) on board the AIM satellite (Russell et al., 2009) provide water vapour and temperature measurements with high vertical resolution in the area covered by the tomographic retrievals during the time period of the tomographic measurements.

ACE-FTS is a Fourier transform spectrometer which measures solar radiation between $750-4400 \mathrm{~cm}^{-1}$ and retrieves water vapour and temperature profiles (Boone et al., 2005) between 5-90 km with an altitude resolution of 3-4 km and a precision of $\sim 300 \mathrm{ppbv}$ for water vapour (statistical fitting error and "form-factor" error Boone et al., 2013) and $\sim 2 \mathrm{~K}$ for temperature (comparison to LIDAR Sica et al., 2008). In this study we use version 3.0 of the water vapour data (Boone et al., 2013), which provides data during July 2010 in the time period covered by tomographic retrievals.

SOFIE uses differential absorption spectroscopy at 11 different wavelengths between 0.292 to $5.316 \mu \mathrm{m}$ to determine the temperature and the atmospheric composition. It retrieves water vapour and temperature between 20 and $95 \mathrm{~km}$ with a vertical resolution of $1-2 \mathrm{~km}$. The precision for water 
(a)

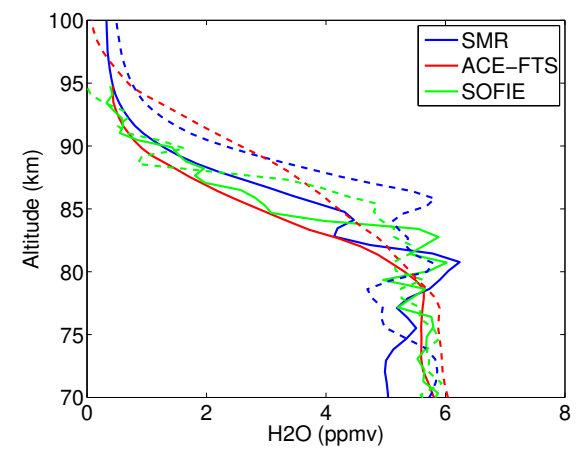

(b)

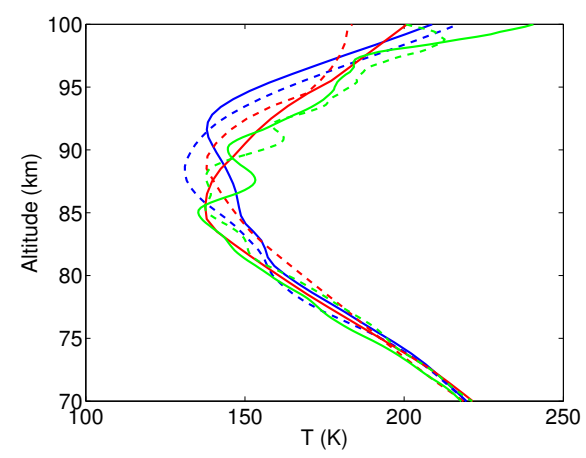

Figure 12. (a) Water vapour profiles from orbit 51226 at $68^{\circ} \mathrm{N}, 81^{\circ} \mathrm{E}$ (dashed lines) and $68^{\circ} \mathrm{N}, 63^{\circ} \mathrm{W}$ (solid lines) from SMR (blue), with collocated ACE-FTS (red) and SOFIE (green) measurements. (b) The corresponding temperature profiles.

vapour is estimated to be better than $0.2 \mathrm{ppmv}$ across the mesopause (Rong et al., 2010), and for temperature the precision is estimated to $0.1 \mathrm{~K}$ at $80 \mathrm{~km}$ increasing up to $0.5 \mathrm{~K}$ at $95 \mathrm{~km}$ (Stevens et al., 2012). In this study we use version 1.2 of the data which covers the entire time period of the tomographic Odin measurements.

The measurements are collocated by finding the retrieved SMR profile at the latitude of ACE-FTS/SOFIE measurements and comparing it to the closest (spatially) ACEFTS/SOFIE during the same day. Due to the different orbits of the satellites there is some distance between the collocated measurements, but $90 \%$ of the collocations are within $350 \mathrm{~km}$. This means that some differences between the profiles due to natural variability should be expected. Another reason for discrepancies between the measurements is that, while SOFIE and ACE-FTS perform measurements at $\sim$ 23:00 and $\sim$ 01:00 LT due to their solar occultation technique, SMR measurements are performed around 17:00 LT. Furthermore, the occultation measurements are made perpendicular to the orbit, i.e. east-west, while SMR measures along the orbit, i.e. north-south. The differences due to sampling different air, however, should largely average out (except possible diurnal variations) when comparing data over the entire PMC season.

The result from SMR orbit 51226 (15 July 2010) is compared to AIM-SOFIE and ACE-FTS in Fig. 12. The position of the collocations are showed by the vertical black lines in Fig. 7. The solid and dashed lines in Fig. 12 are the collocations at $\mathrm{AAO}=70^{\circ}$ and $\mathrm{AAO}=110^{\circ}$ respectively. The data from the three instruments are interpolated onto a common altitude grid for intercomparison to minimise the effect of the retrieved pressure differences between the instruments. For water vapour the agreement between the instruments is good, but SMR seems to show too low values below $80 \mathrm{~km}$. The retrieved temperature of the three instruments have larger differences above $85 \mathrm{~km}$. For the profile measured at $63^{\circ} \mathrm{W}$ (dashed lines) SMR and ACE-FTS places the mesopause at the same altitude $(90 \mathrm{~km})$, while the profile from SOFIE shows the mesopause at $86 \mathrm{~km}$. SMR does however measure a significantly lower mesopause temperature $(<130 \mathrm{~K})$ than the two other instruments. At $81^{\circ} \mathrm{E}$ (solid lines), SMR places the mesopause at a higher altitude than both ACE-FTS and SOFIE. These differences might be, as previously mentioned, due to different sampling time/location. In conclusion, the comparison of the single measurement points show that the tomographic measurements successfully can retrieve water vapour and temperature structures in the area of interest.

To look at the systematic errors in the tomographic retrievals, the mean of all measurements collocated with SOFIE is analysed. A total of 198 collocations are investigated, and Fig. 13a and b show the result of this comparison with respect to each of the two frequency modes of SMR. The measurements using mode 19 show a low bias compared to SOFIE in both water vapour $(>0.5 \mathrm{ppmv})$ and temperature $(>15 \mathrm{~K})$. The estimated accuracy of SOFIE is $\sim 5 \% / 0.8 \mathrm{~K}$ at $80 \mathrm{~km}$ and $15 \% / 9.9 \mathrm{~K}$ at $95 \mathrm{~km}$ for water vapour (Rong et al., 2010) and temperature (Stevens et al., 2012) respectively. Taking this into account the agreement between SMR and SOFIE is good for mode 13, but not for mode 19. Above $85 \mathrm{~km}$ a large difference in mean temperature can be seen $(>30 \mathrm{~K})$. This is partially explained by a known high bias in SOFIE (Stevens et al., 2012). However, comparing SMR and ACE-FTS for July 2010 (not shown), a similar, albeit smaller $(5 \mathrm{~K})$, cold bias is seen above $85 \mathrm{~km}$, and SMR places the mesopause about $2 \mathrm{~km}$ higher than ACEFTS. Thus, we cannot rule out the possibility of a cold bias of $\sim 5 \mathrm{~K}$ above $85 \mathrm{~km}$ even in the frequency mode 13 measurements, though these differences are within combined accuracy of the two instruments.

The comparison of the mean profiles can be extended by looking at the mean profile from each month for SOFIE and SMR. Figure 11c shows the mean water vapour profiles from both instruments for June, July and August averaged over 2010 and 2011. Only the collocations from the frequency mode 13 measurements are used. In June, SOFIE 
(a)

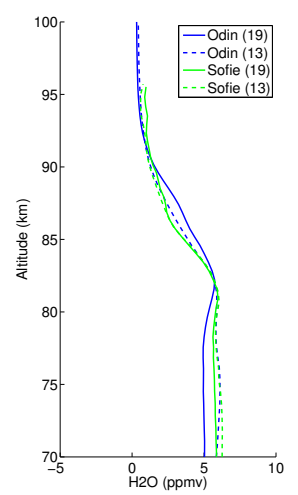

(b)

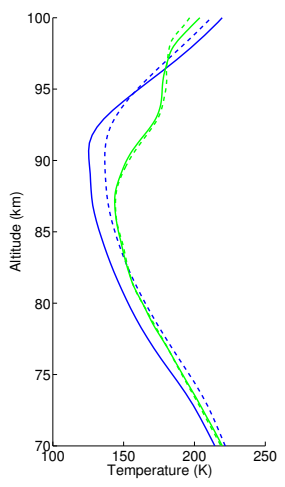

(c)

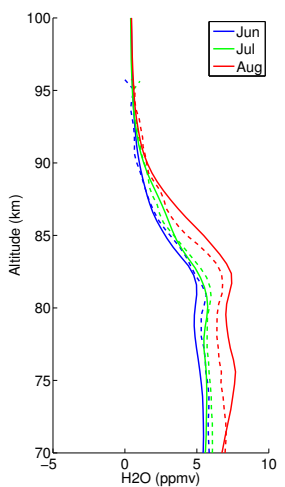

(d)

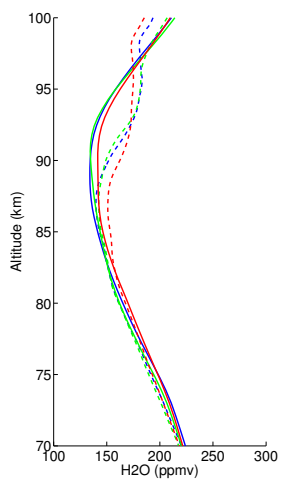

Figure 13. Mean water vapour (a) and temperature (b) profiles from SMR (blue) and collocated SOFIE measurements (green). The measurements where SMR is operating in frequency mode 19/13 are given by the dashed and solid lines respectively. Mean water vapour (c) and temperature (d) profiles from SMR (solid) and collocated SOFIE measurements (dashed) for June (blue), July (green) and August (red). For (c) and (d) only measurements using frequency mode 13 are considered.

(blue-dashed line) shows a higher water vapour concentration below $82 \mathrm{~km}$ than SMR (blue line), while in August (red lines) the reverse is true. The reason for the larger seasonal variation in water vapour in SMR is unknown, but it could be linked to systematic errors in the pressure a priori used for the retrievals. The mean temperature (Fig. 13d) is very similar for both SMR and SOFIE for June and July, while for August SOFIE retrieves a much higher mesopause temperature $(155 \mathrm{~K})$ compared to SMR $(140 \mathrm{~K})$.

It should be noted that the measured water vapour mixing ratios are first converted to number density, before they are rescaled using a common pressure and temperature profile during the comparisons. This means that in principle number density profiles are compared rather than mixing ratios. Doing this mitigates errors arising from the lack of pressure information in the SMR measurements.

In conclusion, the overall agreement between the SMR tomographic measurements and the two solar occulting instruments are within the accuracy estimations from Sect. 5.2 for the measurements made with frequency mode 13. For the measurements made with mode 19 however there is a clear systematic low bias in both water vapour and temperature. The measurements from SMR also show a larger seasonal variance of water vapour, with lower concentrations than SOFIE in June and higher concentrations in August.

\subsection{Comparison to OSIRIS}

As previously mentioned, one of the reason for doing the tomographic SMR measurements is that measurements by OSIRIS are able to retrieve PMC coverage at the same time. Figure 14 shows some example results combining measurements from both instruments. The left panels show the water vapour distribution around PMCs from two different orbits recorded on 15 July 2010. The white contours show the volume scattering coefficient from the PMCs measured by
OSIRIS. The most striking feature is the strong depletion of water vapour above the clouds. This is seen particularly well above each of the three cloudy areas at 80,90 and $100^{\circ}$ AAO in Fig. 14c. At $82 \mathrm{~km}$, there are areas with higher water vapour concentrations between the clouds, indicating possible cloud deposition. In Fig. 14a the water vapour is concentrated in a single area at $80^{\circ}$ AAO. The reason for this feature cannot be explained by looking at the cloud distribution alone, but probably arises as a combination of air movement as well as cloud formation and particle sedimentation.

The atmospheric temperatures are shown in the rightmost panels in Fig. 14. In general, the existence of clouds seem to correlate with the cold areas at $82 \mathrm{~km}$. In particular the warmer area seen at $90-100^{\circ}$ AAO in Fig. 14d has a noticeable lack of clouds compared to the areas around it. This fits well with the water vapour analysis, indicating that this as a possible area of PMC sublimation. In some areas, however, the clouds penetrate into areas of higher temperature $(>150 \mathrm{~K})$; explaining these intrusions requires further analysis taking into account both cloud microphysics and the dynamics of the atmosphere.

\section{Conclusions}

Water vapour and temperature have been measured around PMC by several ground- and satellite-based instruments in the past, but until now, simultaneous measurements of water vapour, temperature and PMC with a large geographical coverage and relatively good vertical and horizontal resolution have not existed. During the arctic summers of 2010 and 2011 the Odin satellite made a set of measurements with both Odin-SMR and Odin-OSIRIS to obtain such data.

In this paper we present the measurements of water vapour and temperature carried out by the SMR instrument. A tomographic retrieval approach based on the optimal estimation 

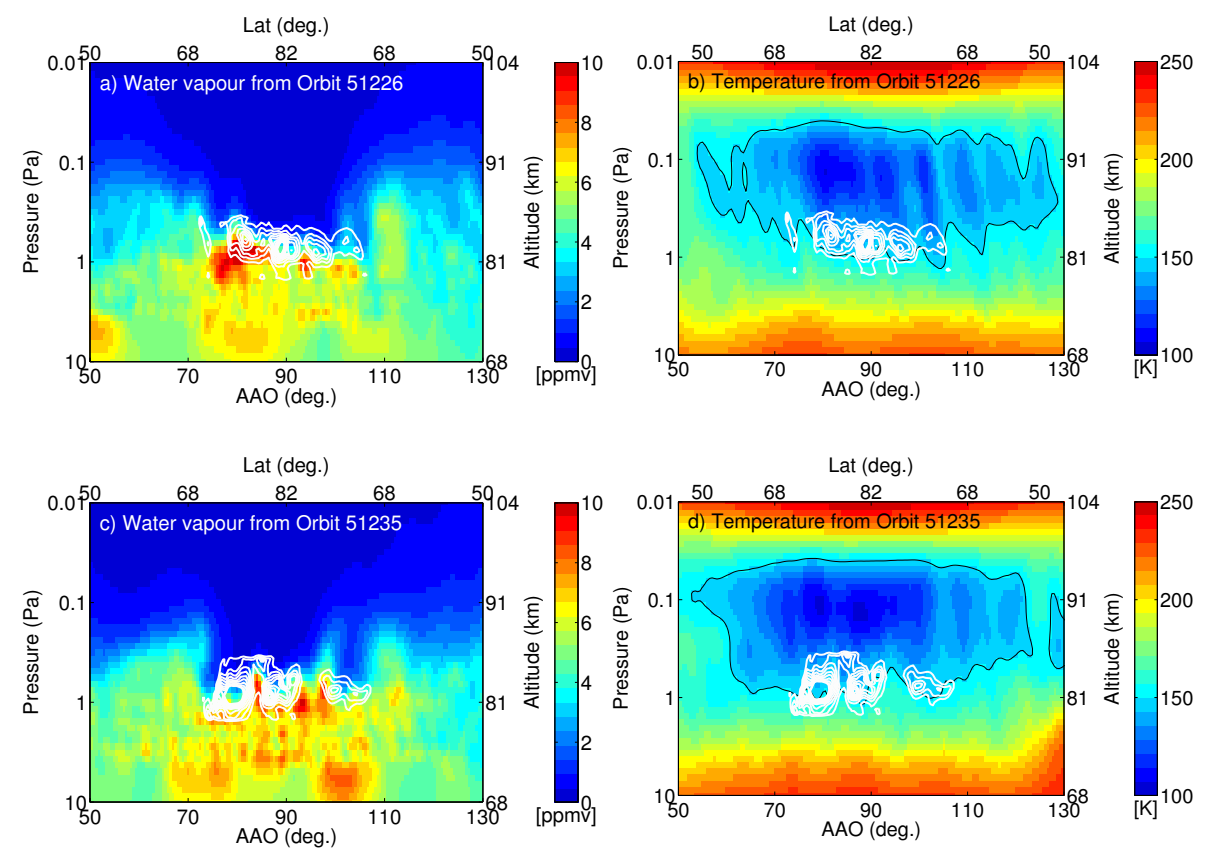

Figure 14. Water vapour (left column) and temperature (right column) fields from two orbits 15 July 2010. The white contours show the volume scattering coefficient from OSIRIS, where each contour corresponds to $1 \times 10^{-9} \mathrm{~m}^{-1} \mathrm{str}^{-1}$. The $150 \mathrm{~K}$ temperature contour is given by the black line in the temperature panels. The lower $x$-axis shows the AAO and the top axis shows the true latitude of the measurements.

method is applied, and is described in detail. An error analysis was performed to investigate possible sources of errors in the retrieved data, and the data were compared to two other satellite instruments for quality assurance.

The largest source of errors in the data comes from the uncertainty in the satellite pointing and the altitude of the $2.9 \mathrm{~Pa}$ pressure level, which is used as the reference level to adjust the atmosphere to remain in HSE. These large uncertainties indicate that the tomographic retrievals have limited capability to retrieve the mean water vapour mixing ratio for each orbit. However, the retrieved variations of water vapour around this mean are significantly less affected by these errors, and can be retrieved by the measurements with reasonable accuracy.

Inspecting the retrievals corresponding to the different frequency modes of SMR revealed discrepancies between measurements done using frequency mode 19 and 13. By comparing the results to collocated AIM-SOFIE measurements, we conclude that the best results are achieved with the frequency mode 13 measurements, which had the lowest systematic differences compared to AIM-SOFIE of the two modes. A larger seasonal variation in water vapour was found in SMR compared to AIM-SOFIE. The reason for these systematic differences is not clear, but it is probably a combination of errors in the modelling of the SMR instrument, and errors in the assumptions about the forward model atmosphere. The differences between the measurements are within our estimated systematic uncertainty for the tomographic measurements.
Despite these uncertainties, the SMR tomographic measurements provide a unique and useful complement to existing data sets. As an example of the capabilities of the measurements, we compared the retrieved atmosphere to PMC extinction coefficients measured by OSIRIS for two of the recorded orbits. The results from the two instruments showed both depletion and enhancement of water vapour around the clouds as well as larger-scale horizontal variation in both water vapour and temperature. To explain the complete water vapour and temperature fields of the background atmosphere requires a more thorough analysis, taking into account both cloud microphysics as well as atmospheric dynamics. Future plans include using the data set to evaluate atmospheric and cloud models, and thus improve our understanding of PMCs and their effect on and response to the background atmosphere under which they form.

Acknowledgements. We would like to thank Kaley Walker and the ACE-FTS/SCISAT team as well as Mark Hervig and the SOFIE/AIM team for providing satellite data of water vapour and temperature for comparison. The Atmospheric Chemistry Experiment (ACE), also known as SCISAT, is a Canadian-led mission mainly supported by the Canadian Space Agency and the Natural Sciences and Engineering Research Council of Canada.

AIM/SOFIE is funded by NASA's Small Explorers Program. The SOFIE v1.2 data used in this work are available online at sofie.gats-inc.com.

Odin is a Swedish-led satellite project funded jointly by the Swedish National Space Board (SNSB), the Canadian Space 
Agency (CSA), the National Technology Agency of Finland (Tekes), the Centre National d'études Spatiales (CNES) in France and the European Space Agency (ESA).

Finally we would like to thank the Associate Editor Thomas von Clarmann and the two anonymous referees for their comments and suggestions which certainly helped improving the quality of both the paper and the results presented herein.

Edited by: T. von Clarmann

\section{References}

Baron, P., Ricaud, P., de la Noë, J., Eriksson, P., Merino, F., and Murtagh, D.: Studies for the Odin sub-millimetre radiometer: retrieval methodology, Can. J. Phys., 80, 341-356, 2002.

Bernath, P. F., McElroy, C. T., Abrams, M. C., Boone, C. D., Butler, M., Camy-Peyret, C., Carleer, M., Clerbaux, C., Coheur, P.-F., Colin, R., DeCola, P., DeMazière, M., Drummond, J. R., Dufour, D., Evans, W. F. J., Fast, H., Fussen, D., Gilbert, K., Jennings, D. E., Llewellyn, E. J., Lowe, R. P., Mahieu, E., McConnell, J. C., McHugh, M., McLeod, S. D., Michaud, R., Midwinter, C., Nassar, R., Nichitiu, F., Nowlan, C., Rinsland, C. P., Rochon, Y. J., Rowlands, N., Semeniuk, K., Simon, P., Skelton, R., Sloan, J. J., Soucy, M.-A., Strong, K., Tremblay, P., Turnbull, D., Walker, K. A., Walkty, I., Wardle, D. A., Wehrle, V., Zander, R., and Zou, J.: Atmospheric chemistry experiment (ACE): mission overview, Geophys. Res. Lett., 32, L15S01, doi:10.1029/2005GL022386, 2005.

Boone, C. D., Nassar, R., Walker, K. A., Rochon, Y., McLeod, S. D., Rinsland, C. P., and Bernath, P. F.: Retrievals for the atmospheric chemistry experiment Fourier-transform spectrometer, Appl. Optics, 44, 7218-7231, doi:10.1364/AO.44.007218, 2005.

Boone, C. D., Walker, K. A., and Bernath, P. F.: Retrievals for the Atmospheric Chemistry Experiment Fourier Transform Spectrometer (ACE-FTS), in: The Atmospheric Chemistry Experiment ACE at 10: A Solar Occultation Anthology, edited by: Bernath, P. F., A. Deepak Publishing, Hampton, Virginia, USA, 2013.

Buehler, S. A., Eriksson, P., Kuhn, T., von Engeln, A., and Verdes, C.: ARTS, the Atmospheric Radiative Transfer Simulator, J. Quant. Spectrosc. Ra., 91, 65-93, 2005.

Carlotti, M., Dinelli, B. M., Raspollini, P. and Ridolfi, M.: Geofit approach to the analysis of limb-scanning satellite measurements, Appl. Opt., 40, 1872-1885, doi:10.1364/AO.40.001872, 2001.

Carlotti, M., Brizzi, G., Papandrea, E., Prevedelli, M., Ridolfi, M., Dinelli, B. M. and Magnani, L.: GMTR: Two-dimensional geofit multitarget retrieval model for Michelson Interferometer for Passive Atmospheric Sounding/Environmental Satellite observations, Appl. Opt., 45, 716-727, doi:10.1364/AO.45.000716, 2006.

Ceccherini, S. and Ridolfi, M.: Technical Note: Variance-covariance matrix and averaging kernels for the Levenberg-Marquardt solution of the retrieval of atmospheric vertical profiles, Atmos. Chem. Phys., 10, 3131-3139, doi:10.5194/acp-10-3131-2010, 2010 .
Degenstein, D. A., Llewellyn, E. J., and Lloyd, N. D.: Volume emission rate tomography from a satellite platform, Appl. Optics, 42, 1441-1450, 2003.

Eriksson, P., Merino, F., Murtagh, D., Baron, P., Ricaud, P., and de la Noë, J.: Studies for the Odin sub-millimetre radiometer: 1. Radiative transfer and instrument simulation, Can. J. Phys., 80, 321-340, 2002.

Eriksson, P., Jiménez, C., Bühler, S. ans Murtagh, D.: A Hotelling transformation approach for rapid inversion of atmospheric spectra, J. Quant. Spectrosc. Radiat. Transfer, 73, 529-543, 2002.

Eriksson, P., Ekström, M., Bühler, S. A., and Melsheimer, C.: Efficient forward modelling by matrix representation of sensor responses, Int. J. Remote Sens., 27, 1793-1808, 2006.

Eriksson, P., Bühler, S., Davis, C., Emde, C., and Lemke, O.: ARTS, the atmospheric radiative transfer simulator, version 2, J. Quant. Spectrosc. Ra., 112, 1551-1558, doi:10.1016/j.jqsrt.2011.03.001, 2011.

Feofilov, A. G., Kutepov, A. A., Pesnell, W. D., Goldberg, R. A., Marshall, B. T., Gordley, L. L., García-Comas, M., LópezPuertas, M., Manuilova, R. O., Yankovsky, V. A., Petelina, S. V., and Russell III, J. M.: Daytime SABER/TIMED observations of water vapor in the mesosphere: retrieval approach and first results, Atmos. Chem. Phys., 9, 8139-8158, doi:10.5194/acp-98139-2009, 2009.

Fleming, E. L., Chandra, S., Barnett, J., and Corney, M.: Zonal mean temperature, pressure, zonal wind and geopotential height as functions of latitude, Adv. Space Res., 10, 11-59, doi:10.1016/0273-1177(90)90386-E, 1990.

Frisk, U., Hagström, M., Ala-Laurinaho, J., Andersson, S., Berges, J.-C., Chabaud, J.-P., Dahlgren, M., Emrich, A., Florén, H.-G., Florin, G., Fredrixon, M., Gaier, T., Haas, R., Hirvonen, T., Hjalmarsson, Å., Jakobsson, B., Jukkala, P., Kildal, P. S., Kollberg, E., Lassing, E., Lecacheux, A., Lehikoinen, P., Lehto, A., Mallat, J., Marty, C., Michet, D., Narbonne, J., Nexon, M., Olberg, M., Olofsson, A. O. H., Olofsson, G., Origné, A., Petersson, M., Piironen, P., Pons, R., Pouliquen, D., Ristorcelli, I., Rosolen, C., Rouaix, G., Räisänen, A. V., Serra, G., Sjöberg, F., Stenmark, L., Torchinsky, S., Tuovinen, J., Ullberg, C., Vinterhav, E., Wadefalk, N., Zirath, H., Zimmermann, P., and Zimmermann, R.: The Odin satellite. I. Radiometer design and test, Astron. Astrophys., 402, L27-L34, 2003.

Hedin, A. E.: Extension of the MSIS thermosphere model into the middle and lower atmosphere, J. Geophys. Res., 96, 1159-1172, doi:10.1029/90JA02125, 1991.

Hervig, M. E., Stevens, M. H., Gordley, L. L., Deaver, L. E., Russell, J. M., and Bailey, S. M.: Relationships between polar mesospheric clouds, temperature, and water vapor from Solar Occultation for Ice Experiment (SOFIE) observations, J. Geophys. Res., 114, D20203, doi:10.1029/2009JD012302, 2009.

Hultgren, K., Gumbel, J., Degenstein, D., Bourassa, A., Lloyd, N., and Stegman, J.: First simultaneous retrievals of horizontal and vertical structures of Polar Mesospheric Clouds from Odin/OSIRIS tomography, J. Atmos. Sol.-Terr. Phy., 104, 213 223, doi:10.1016/j.jastp.2013.06.013, 2013.

Lübken, F.-J., Jarvis, M. J., and Jones, G. O. L.: First in situ temperature measurements at the Antarctic summer mesopause, Geophys. Res. Lett., 26, 3581-3584, doi:10.1029/1999GL010719, 1999. 
Livesey, N., Van Snyder, W., Read, W., and Wagner, P.: Retrieval algorithms for the EOS Microwave limb sounder (MLS), IEEE T. Geosci. Remote, 44, 1144-1155, doi:10.1109/TGRS.2006.872327, 2006.

Lossow, S., Urban, J., Eriksson, P., Murtagh, D., and Gumbel, J.: Critical parameters for the retrieval of mesospheric water vapour and temperature from Odin/SMR limb measurements at $557 \mathrm{GHz}$, Adv. Space Res., 40, 835-845, 2007.

Lossow, S., Urban, J., Schmidt, H., Marsh, D., Gumbel, J., Eriksson, P., and Murtagh, D.: Wintertime water vapor in the polar upper mesosphere and lower thermosphere: first satellite observations by Odin submillimeter radiometer, J. Geophys. Res., 114, D10304, doi:10.1029/2008JD011462, 2009.

López-Puertas, M., García-Comas, M., Funke, B., BermejoPantaleón, D., Höpfner, M., Grabowski, U., Stiller, G. P., von Clarmann, T., and von Savigny, C.: Measurements of polar mesospheric clouds in infrared emission by MIPAS/ENVISAT, J. Geophys. Res., 114, D00I07, doi:10.1029/2009JD012548, 2009.

Lübken, F.-J., Rapp, M., and Strelnikova, I.: The sensitivity of mesospheric ice layers to atmospheric background temperatures and water vapor, Adv. Space Res., 40, 794-801, 2007.

McHugh, M., Hervig, M., Magill, B., Thompson, R. E., Remsberg, E., Wrotny, J., and Russell III, J.: Improved mesospheric temperature, water vapor and polar mesospheric cloud extinctions from HALOE, Geophys. Res. Lett., 30, 1440, doi:10.1029/2002GL016859, 2003.

Murtagh, D., Frisk, U., Merino, F., Ridal, M., Jonsson, A., Stegman, J., Witt, G., Eriksson, P., Jiménez, C., Megie, G., de la Noë, J., Ricaud, P., Baron, P., Pardo, J. R., Hauchcorne, A., Llewellyn, E. J., Degenstein, D. A., Gattinger, R. L., Lloyd, N. D., Evans, W. F. J., McDade, I. C., Haley, C., Sioris, C., von Savigny, C., Solheim, B. H., McConnell, J. C., Strong, K., Richardson, E. H., Leppelmeier, G. W., Kyrölä, E., Auvinen, H., and Oikarinen, L.: An overview of the Odin atmospheric mission, Can. J. Phys., 80, 309-319, 2002.

Pickett, H., Poynter, R., Cohen, E., Delitsky, M., Pearson, J., and Muller, H.: Submillimeter, millimeter, and microwave spectral line catalog, J. Quant. Spectrosc. Rad., 60, 883-890, 1998.

Puķīe, J., Kühl, S., Deutschmann, T., Platt, U., and Wagner, T.: Accounting for the effect of horizontal gradients in limb measurements of scattered sunlight, Atmos. Chem. Phys., 8, 3045-3060, doi:10.5194/acp-8-3045-2008, 2008.

Rapp, M. and Thomas, G. E.: Modeling the microphysics of mesospheric ice particles: assessment of current capabilities and basic sensitivities, J. Atmos. Sol.-Terr. Phy., 68, 715-744, 2006.

Raspollini, P., Carli, B., Carlotti, M., Ceccherini, S., Dehn, A., Dinelli, B. M., Dudhia, A., Flaud, J.-M., López-Puertas, M., Niro, F., Remedios, J. J., Ridolfi, M., Sembhi, H., Sgheri, L., and von Clarmann, T.: Ten years of MIPAS measurements with ESA Level 2 processor V6 - Part 1: Retrieval algorithm and diagnostics of the products, Atmos. Meas. Tech., 6, 2419-2439, doi:10.5194/amt-6-2419-2013, 2013.

Rodgers, C.: Inverse Methods for Atmospheric Sounding: Theory and Practice, World Scientific, Singapore, 2000.

Rong, P., Russell, J. M., Gordley, L. L., Hervig, M. E., Deaver, L., Bernath, P. F., and Walker, K. A.: Validation of v1. 022 mesospheric water vapor observed by the Solar Occultation for Ice Experiment instrument on the Aeronomy of Ice in the Mesosphere satellite, J. Geophys. Res., 115, D24314, doi:10.1029/2010JD014269, 2010.

Rong, P., Russell, J., Hervig, M., and Bailey, S.: The roles of temperature and water vapor at different stages of the polar mesospheric cloud season, J. Geophys. Res., 117, D04208, doi:10.1029/2011JD016464, 2012.

Rong, P. P., Russell, J. M., Randall, C. E., Bailey, S. M., and Lambert, A.: Northern PMC brightness zonal variability and its correlation with temperature and water vapor, J. Geophys. Res.Atmos., 119, 2390-2408, doi:10.1002/2013JD020513, 2014.

Rothman, L. S., Gordon, I. E., Babikov, Y., Barbe, A., Chris Benner D., Bernath, P. F., Birk, M., Bizzocchi, L., Boudon, V., Brown, L. R., Campargue, A., Chance, K., Cohen, E. A., Coudert, L. H., Devi, V. M., Drouin, B. J. Fayt, A., Flaud, J.-M., Gamache, R. R., Harrison, J. J., Hartmann, J.-M., Hill, C., Hodges, J. T., Jacquemart, D., Jolly, A., Lamouroux, J., Le Roy, R. J., Li, G., Long, D. A., Lyulin, O. M., Mackie, C. J., Massie, S. T., Mikhailenko, S., Müller, H. S. P., Naumenko, O. V., Nikitin, A. V., Orphal, J., Perevalov, V., Perrin, A., Polovtseva, E. R., Richard, C., Smith, M. A. H., Starikova, E., Sung, K., Tashkun, S., Tennyson, J., Toon, G. C., Tyuterev, Vl. G., and Wagner, G.: The HITRAN2012 molecular spectroscopic database, J. Quant. Spectrosc. Ra., 130, 4-50, doi:10.1016/j.jqsrt.2013.07.002, 2013.

Russell, J. M., Bailey, S. M., Gordley, L. L., Rusch, D. W., Horányi, M., Hervig, M. E., Thomas, G. E., Randall, C. E., Siskind, D. E., Stevens, M. H., Summers, M. E., Taylor, M. J., Englert, C. R., Espy, P. J., McClintock, W. E., and Merkel, A. W.: The Aeronomy of Ice in the Mesosphere (AIM) mission: overview and early science results, J. Atmos. Sol.-Terr. Phy., 71, 289-299, doi:10.1016/j.jastp.2008.08.011, 2009.

Seele, C. and Hartogh, P.: Water vapor of the polar middle atmosphere: annual variation and summer mesosphere conditions as observed by ground-based microwave spectroscopy, Geophys. Res. Lett., 26, 1517-1520, doi:10.1029/1999GL900315, 1999.

Seta, T., Hoshina, H., Kasai, Y., Hosako, I., Otani, C., Lossow, S., Urban, J., Ekström, M., Eriksson, P., and Murtagh, D. P.: Pressure broadening coefficients of the water vapor lines at 556.936 and 752.033 GHz, J. Quant. Spectrosc. Rad., 109, 144-150, 2008.

Sheese, P. E., Llewellyn, E. J., Gattinger, R. L., Bourassa, A. E., Degenstein, D. A., Lloyd, N. D., and McDade, I. C.: Mesopause temperatures during the polar mesospheric cloud season, Geophys. Res. Lett., 38, L11803, doi:10.1029/2011GL047437, 2011.

Sica, R. J., Izawa, M. R. M., Walker, K. A., Boone, C., Petelina, S. V., Argall, P. S., Bernath, P., Burns, G. B., Catoire, V., Collins, R. L., Daffer, W. H., De Clercq, C., Fan, Z. Y., Firanski, B. J., French, W. J. R., Gerard, P., Gerding, M., Granville, J., Innis, J. L., Keckhut, P., Kerzenmacher, T., Klekociuk, A. R., Kyrö, E., Lambert, J. C., Llewellyn, E. J., Manney, G. L., McDermid, I. S., Mizutani, K., Murayama, Y., Piccolo, C., Raspollini, P., Ridolfi, M., Robert, C., Steinbrecht, W., Strawbridge, K. B., Strong, K., Stübi, R., and Thurairajah, B.: Validation of the Atmospheric Chemistry Experiment (ACE) version 2.2 temperature using ground-based and space-borne measurements, Atmos. Chem. Phys., 8, 35-62, doi:10.5194/acp-8-35-2008, 2008.

Steck, T., Höpfner, M., von Clarmann, T., and Grabowski, U.: Tomographic retrieval of atmospheric parameters from infrared limb emission observations, Appl. Optics, 44, 3291-3301, doi:10.1364/AO.44.003291, 2005. 
Stevens, M. H., Deaver, L. E., Hervig, M. E., Russell, J. M., Siskind, D. E., Sheese, P. E., Llewellyn, E. J., Gattinger, R. L., Höffner, J., and Marshall, B.: Validation of upper mesospheric and lower thermospheric temperatures measured by the Solar Occultation for Ice Experiment, J. Geophys. Res., 117, D16304, doi:10.1029/2012JD017689, 2012.

Thomas, G. E., Olivero, J. J., Jensen, E. J., Schroeder, W., and Toon, O. B.: Relation between increasing methane and the presence of ice clouds at the mesopause, Nature, 338, 490-492, 1989.

Thomas, G. E., Olivero, J. J., Deland, M., and Shettle, E. P. E. P.: Comment on "Are noctilucent clouds truly a "Miner's Canary" for Global Change?”, Eos T. Am. Geophys. Un., 84, 352-353, 2003. von Clarmann, T., De Clercq, C., Ridolfi, M., Höpfner, M., and Lambert, J.-C.: The horizontal resolution of MIPAS, Atmos. Meas. Tech., 2, 47-54, doi:10.5194/amt-2-47-2009, 2009.

von Zahn, U.: Are noctilucent clouds a "Miner's Canary" for global change?, Eos T. Am. Geophys. Un., 84, 261-264, doi:10.1029/2003EO280001, 2003.

Zasetsky, A., Petelina, S., Remorov, R., Boone, C., Bernath, P., and Llewellyn, E.: Ice particle growth in the polar summer mesosphere: formation time and equilibrium size, Geophys. Res. Lett., 36, L15803, doi:10.1029/2009GL038727, 2009. 